\title{
Phenotypic and genotypic diversity of fluorescent pseudomonads isolated from field- grown sugar beet
}

\author{
Paul B. Rainey, † Mark J. Bailey and Ian P. Thompson \\ Author for correspondence: Ian P. Thompson. Tel: +44865 512361. Fax: + 4486559962.
}

Molecular Microbial

Ecology, Institute of Virology and Environmental Microbiology, Mansfield Road, Oxford OX1 3SR, UK

\begin{abstract}
A sample of $\mathbf{3 0}$ fluorescent pseudomonads isolated from the phyllosphere of sugar beet throughout a single growing season and shown to be closely related on the basis of fatty acid methyl ester (FAME) analysis was subjected to detailed phenotypic and genotypic characterization. Phenotypic traits were assessed on the basis of biochemical properties, assimilation of sole carbon sources, FAME analysis, organic pyrolysate content (MS-pyrolysis), and total cellular protein profiles. With the exception of total cellular protein profiles, numerical analysis of the data revealed two main clusters, each of which was divided into several subclusters. Numerical analysis of total cellular protein data failed to differentiate isolates into two main clusters, but nevertheless grouped isolates into six subclusters. On the basis of biochemical and carbon source assimilation profiles, 19 isolates were identified as Pseudomonas fluorescens biovar $\mathbf{V}$, eight isolates as $P$. fluorescens biovar III and three isolates as $\boldsymbol{P}$. syringae pathovar syringae. In general, all methods of phenotypic analysis grouped isolates according to time of sampling and leaf type. Genome analysis was undertaken by pulsed-field gel electrophoresis (PFGE) of Pacl, Spel, Swal and Xbal macrorestriction fragments and revealed the presence of eight distinct genomic (clonal) groups. These groups correlated closely with the clusters generated by numerical analysis of phenotypic data, but there was no correlation between macrorestriction fragment profile and isolate identification; in fact the variation in macrorestriction fragment patterns within $P$. fluorescens biovars was as great as the variation detected between biovars, and between $P$. fluorescens and $P$. syringae. Statistical evaluation of macrorestriction fragment patterns revealed two examples of recent strain divergence: one was due to the presence of a $\mathbf{4 0 0} \mathrm{kbp}$ plasmid within one isolate of a collection of nine otherwise genomically identical isolates, and the other was observed between two phenotypically similar isolates sampled $220 \mathrm{~d}$ apart. Genetic variation was expressed in terms of nucleotide diversity $(\pi)$ and pairwise comparisons yielded values ranging from 0.0029 to 0.1517 . The mean intrapopulation genetic variation was high (0.0993), but limited genetic variation was detected among isolates sampled on each occasion. Taken together this suggests a population comprised of a variety of apparently distantly related clones (genomic groups), each adapted to local conditions. Genome sizes were estimated from the sum of Spel restriction fragments and ranged from 4.2 to 5.5 Mbp. Examination of the distribution of Xbal, Spel, Swal and Pacl restriction endonuclease sites showed that the distribution of Spel sites differed significantly from the expected (random) distribution.
\end{abstract}

Keywords: fluorescent pseudomonads, phyllosphere, population analysis, systematics, environmental microbiology
†Present address: Department of Plant Sciences, University of Oxford, South Parks Road, Oxford OX1 3RB, UK.

Abbreviations: FAME, fatty acid methyl ester; PFGE, pulsed-field gel electrophoresis; RFLP, restriction fragment length polymorphism; UPGMA, unweighted pair-group method with arithmetic averages.

\section{INTRODUCTION}

Fluorescent pseudomonads are prodigious colonizers of plants and occur in large numbers on leaf surfaces (the phyllosphere; Van Outryve et al., 1989; Ercolani, 1991; 
Hirano \& Upper, 1993; Thompson et al., 1993a), roots, and in the soil immediately adjacent to the root where microbial activity is affected by the plant (the rhizosphere; O'Sullivan \& O'Gara, 1992). The intimate nature of the association between pseudomonad and plant is such that bacterial activity can markedly affect plant growth. Certain pseudomonads, including Pseudomonas syringae and $P$. viridiflava, can cause disease (Palleroni, 1984), while others, such as isolates of $P$. fluorescens and $P$. putida, can promote plant growth (O'Sullivan \& O'Gara, 1992). The majority of phyllosphere-inhabiting fluorescent pseudomonads have no apparent effect on plant growth, but nevertheless represent important components of the leaf community (Austin et al., 1978; Ercolani, 1978; Van Outryve et al., 1989).

Fluorescent pseudomonads represent the largest group of bacteria inhabiting the phyllosphere of field-grown sugrar beet. A recent survey based on fatty acid methyl ester (FAME) analysis showed that $P$. aureofaciens ( $P$. chlororaphis) was the most frequently isolated species and, significantly, it was the only species isolated on every sampling occasion throughout the season (Thompson et al., 1993a). On one particular occasion P. aureofaciens represented up to $83 \%$ of the identified bacterial community (Thompson et al., 1993a). The persistence of $P$. aureofaciens and other closely related fluorescent pseudomonads within the phyllosphere is of interest because of the adaptive traits necessary for survival in the face of frequent and often extreme alterations in temperature, moisture content, UV-irradiation and nutrient status (Dickinson, 1986). The precise nature of these traits and adaptive strategies which enhance survival of bacteria in environments subject to frequent and unpredictatile change are of considerable interest (Lindow, 1993; Rainey et al., 1993a; Moxon et al., 1994).

The persistence of fluorescent pseudomonads in the phyllosphere renders them suitable and desirable candidates for biocontrol programmes targeted at agricultural crops. Phyllosphere-adapted saprophytes may provide plant protection by excluding pathogens from the plant environment; a direct result of their ability to rapidly and aggressively colonize available niches (Wilson \& Lindow, 1993). They may also exclude pathogens by the production of antimicrobial compounds (O'Sullivan \& O'Gara, 1992). In addition, and as a result of the ease with which pseudomonads can be genetically manipulated, such strains are potential hosts for foreign genes targetted at the phyllosphere. However, before embarking upon biocontrol projects involving environmental release an understanding of the structure and diversity of the fluorescent pseudomonad population is essential. In particular, it is necessary to determine whether the apparent adaptability inherent within this species is the result of marked phenotypic plasticity or genetic diversity, or a combination of both.

Studies on the $P$. syringae pv. savastanoi population of olive leaves showed that specific phenotypes were found on different sampling occasions, suggesting that long-term survival is dependent upon phenotypic heterogeneity (Ercolani, 1983, 1985); the extent of genotypic diversity among these isolates was not investigated. Population genetic studies based on allozyme analysis indicate that genetic diversity is correlated with habitat variability (see for example, Denny et al., 1988; McArthur et al., 1988), but whether this is true for all phyllosphere inhabitants remains to be determined.

We have attempted in this study to examine the degree of phenotypic and genotypic diversity within a selection of closely related isolates sampled from one field during the course of a single season. During the 1990 field season, 150 randomly selected bacteria were isolated from three leaf types (immature, mature and senescent) on each of seven sampling occasions and subjected to FAME analysis. Cluster analysis of FAME profiles revealed many different taxonomic groups (Thompson et al., 1993a) one of which, the so-named $P$. aureofaciens cluster, formed the basis of this study.

\section{METHODS}

Isolation of bacteria. Leaf samples were taken from a sugar beet field (Beta vulgaris, var. Amethyst) contained in a $15 \mathrm{~m} \times 15 \mathrm{~m}$ plot at the University Field Station, Wytham, Oxford, UK. Bacteria were sampled on seven different occasions throughout the 1990 growing season: $52 \mathrm{~d}$ (June), $79 \mathrm{~d}$ (July), $114 \mathrm{~d}$ (August), $148 \mathrm{~d}$ (September), $183 \mathrm{~d}$ (November), $220 \mathrm{~d}$ (December) and $272 \mathrm{~d}$ (January) after sowing. Methods of sampling have been described in detail (Thompson et al., 1993a). Briefly, bacteria were isolated from three replicate samples, each of which was divided into three leaf types (immature, mature, and senescent) and each of which represented a pool of leaves collected from three randomly selected plants (plants sampled on day 52 were too young to be differentiated on the basis of leaf type). Each strain was assigned an isolate number which also indicated the replicate from which it was isolated: isolates $1-50$ were isolated from replicate one, isolates $51-100$ were isolated from replicate two and isolates 101-150 were isolated from replicate three. The only exception to this scheme were samples collected on day 79, when 60 isolates were taken from replicate three (isolates 101-160). Each isolate number was prefixed by a sample number indicating the day of isolation, for example, $148 / 128$ was isolated on day 148 from replicate three; similarly, strain 52/76 was isolated on day 52 from replicate two. Of the bacteria identified on each sampling occasion, only those identified in the first instance on the basis of FAME profile as $P$. aureofaciens were selected for further study (122 isolates). Of these, a random sample of 30 isolates was chosen for detailed analysis. Once isolated, all cultures were stored at $-80^{\circ} \mathrm{C}$ and analysed together at the completion of sampling.

Isolation media, culture and storage conditions were as described previously (Thompson et al., 1993a).

Biochemical and carbon source utilization characteristics. Biochemical characteristics of each isolate were assessed using the API20NE standardized micromethod (bioMerieux), which included eight conventional and 12 assimilation tests. Strips were inoculated according to the manufacturer's instructions and incubated for $24 \mathrm{~h}$ at $25^{\circ} \mathrm{C}$ before recording the results. Isolate identification was achieved by comparing the reactions recorded for each isolate with the analytical profile index provided by the manufacturer. 
The ability of isolates to assimilate a range of sole carbon sources was assessed by the auxanographic API system containing 49 sugars (API50CH), 49 amino compounds (API50AA) and 49 organic acids (API50AO). Isolates were grown overnight on Tryptic Soy Broth (TSB) agar at $28{ }^{\circ} \mathrm{C}$ and a suspension of cells $(0 \cdot 14 \mathrm{~g}$ wet weight in $60 \mathrm{ml}$ assimilation medium API150LRA) was used to inoculate each cupule. Strips were incubated at $20^{\circ} \mathrm{C}$ and growth was recorded (slight, moderate or strong) after $1,2,4,8$ and $16 \mathrm{~d}$.

The ability to assimilate each carbon source was treated as a separate unit character. Codes from 0 (negative) to 10 (strongly positive after $1 \mathrm{~d}$ incubation), corresponding to the rate and strength of growth, were assigned to each isolate. These data were then subjected to numerical analysis. Similarities between isolates were calculated with the generalized similarity coefficient and the coefficient based on the Euclidean distance between pairs of isolates. This was achieved using UNISTAT software (UNISTAT, Highgate, London, UK) and isolates were clustered using the unweighted pair group method with arithmetic averages (UPGMA) (Sneath \& Sokal, 1973).

Cellular fatty acid analysis. Isolates for FAME analysis were cultured on TSB agar plates. Cells were harvested after $24 \mathrm{~h}$ incubation at $28{ }^{\circ} \mathrm{C}$ and whole-cell fatty acids were saponified, methylated and extracted as described by Miller \& Berger (1985). F A ME analysis was performed using a Hewlett-Packard model 5890 series II gas chromatograph. All analyses were conducted in triplicate and the mean FAME profiles were used to generate a unique library for each isolate. Fatty acid peaks were named by the Microbial Identification System (MIS) software (Microbial ID, Newark, DE, USA) and isolates identified using the MIS 'Aerobe Library'. Initially all isolates were identified using 'Aerobe Library' version 3.30 (October 1990 update) and subsequently using version 3.50 (October 1991 update). Quantitative data obtained from FAME analysis were subjected to numerical analysis as described previously (Thompson et al., 1993b). Similarities between isolates were calculated using the generalized similarity coefficient of Gower (Gower, 1966) and the coefficient based on the Euclidean distance between pairs of isolates (Bøe \& Gjerde, 1980). Isolate clustering was accomplished using the UPGMA.

Pyrolysis mass spectrometry. The organic pyrolysate contents from triplicate overnight cultures of isolates grown on TSB agar at $28^{\circ} \mathrm{C}$ were analysed using a Horizon Instruments PYMS $200 \mathrm{X}$ pyrolvsis mass spectrometer, as described by Orr et al. (1991). MS-pyrolysis data were subjected to principal com- ponent and canonical variate analysis using GENSTAT (Goodacre \& Berkely, 1990). Data were transformed to a percentage similarity matrix using Gower's similarity coefficient and isolates were clustered using the UPGMA.

Total cellular protein content. Total cellular protein was prepared from $0.5 \mathrm{ml}$ cells removed from an overnight Luria broth (LB) culture using the method of Xu \& Gross (1988) as modified by Rainey et al. (1993b). Proteins were separated on both $6 \%$ and $10 \%(\mathrm{w} / \mathrm{v})$ polyacrylamide gels containing $0.1 \%$ sodium dodecyl sulphate (SDS-PAGE) and stained with Coomassie Brilliant Blue (Laemmli, 1970). Gels were photographed and digitized using a Summa graphics tablet interfaced with Molmatch software (UV Products, Cambridge, UK). Only proteins resolved on $6 \%$ gels were used in subsequent analysis and a measure of similarity between lanes was obtained using the Dice coefficient, $S_{D}$ (see below). Isolates were clustered using the UPGMA.

\section{Pulsed-field gel electrophoresis}

DNA preparation. Unsheared DNA was prepared by embedding whole cells in chromosomal-grade agarose blocks followed by lysis with detergent and proteinase K (Rainey et al., 1993b). One volume of cells grown overnight in $\mathrm{LB}$ was harvested, washed twice in NET-100 buffer $[0.1 \mathrm{M} \mathrm{NaCl}, 0.1 \mathrm{M}$ EDTA, $0.01 \mathrm{M}$ Tris/ $\mathrm{HCl}(\mathrm{pH} 8 \cdot 0)]$, then mixed with an equal volume of molten $0.9 \%$ chromosomal-grade agarose (in NET-100) and dispensed into moulds. Cells were lysed by immersing the agarose blocks in lysis solution I $6 \mathrm{mM}$ Tris/ $\mathrm{HCl}(\mathrm{pH} \mathrm{7.6)}, 1 \mathrm{M} \mathrm{NaCl}, 100 \mathrm{mM}$ EDTA (pH 8.0), 0.5\% sarkosyl, $1 \mathrm{mg}$ lysozyme $\mathrm{ml}^{-1}$ ] for $24 \mathrm{~h}$ at $37^{\circ} \mathrm{C}$. Lysis solution I was then replaced with solution II [0.5 M EDTA (pH 9.0), $1 \%$ sarkosyl, $1.5 \mathrm{mg}$ proteinase $\mathrm{K}$ $\mathrm{ml}^{-1}$ ] and incubation continued for a further $48 \mathrm{~h}$ at $50^{\circ} \mathrm{C}$.

Restriction endonuclease digestion. Restriction endonuclease digestions were conducted as described by Suwanto \& Kaplan (1989), following PMSF treatment. Restriction endonuclease digestions were performed in $1 \times \mathrm{KGB}$ buffer (McClelland et al., 1988) using $8 \mathrm{U}$ enzyme. Reactions containing PacI were incubated at $25^{\circ} \mathrm{C}$ for $6 \mathrm{~h}$; reactions containing XbaI, SpeI and Swal were also incubated for $6 \mathrm{~h}$, but at $37^{\circ} \mathrm{C}$.

Pulsed-field gel electrophoresis. DNA inserts containing approximately $2 \mu \mathrm{g}$ DNA were loaded into $0.5 \times$ TBE-buffered gels. Gels were run in a CHEF DRII pulsed-field electrophoresis system (Bio-Rad) containing $0.5 \times \mathrm{TBE}$ buffer at $200 \mathrm{~V}$ and stained in ethidium bromide $\left(0.5 \mathrm{mg} \mathrm{ml}^{-1}\right)$ for $30 \mathrm{~min}$. Fragment

Table 1. Biochemical characteristics of isolates

\begin{tabular}{|c|c|c|c|c|c|c|c|}
\hline \multirow{2}{*}{$\begin{array}{l}\text { Biochemical } \\
\text { character }\end{array}$} & \multicolumn{7}{|c|}{ Isolate } \\
\hline & $\begin{array}{c}183 / 147,114 / 97,183 / 143,183 / 112 \\
183 / 122,183 / 116,114 / 74,114 / 60 \\
114 / 82,114 / 80,114 / 110,148 / 128 \\
183 / 145,148 / 124\end{array}$ & $79 / 117,272 / 48$ & $\begin{array}{c}114 / 85,114 / 95 \\
148 / 146\end{array}$ & $148 / 102,114 / 147$ & $\begin{array}{c}79 / 45,79 / 13 \\
79 / 2\end{array}$ & $52 / 76$ & $\begin{array}{c}79 / 156,79 / 123, \\
79 / 146,79 / 148, \\
79 / 61\end{array}$ \\
\hline Nitrate reduction & + & + & + & + & - & + & + \\
\hline Arginine dihydrolase & + & + & + & + & - & + & + \\
\hline Urease production & - & + & + & + & - & + & - \\
\hline Aesculin hydrolysis & - & - & - & - & + & + & - \\
\hline Gelatin hydrolysis & + & - & + & - & + & - & - \\
\hline Oxidase & + & + & + & + & - & + & + \\
\hline Maltose & - & - & - & + & - & - & - \\
\hline
\end{tabular}


Table 2. Sole carbon source assimilation characteristics of isolates from clusters/subclusters defined by UPGMA analysis using Euclidean distance

The percentage frequency of features present within each cluster/subcluster is shown. Carbon sources universally utilized or not used by any isolate are given in footnotes.

\begin{tabular}{|c|c|c|c|c|c|c|c|c|}
\hline \multirow{4}{*}{$\begin{array}{r}\text { Cluster... } \\
\text { Subcluster... } \\
\text { Source*... } \\
\text { No. of isolates... }\end{array}$} & \multicolumn{4}{|c|}{$\mathbf{A}$} & \multicolumn{4}{|c|}{ B } \\
\hline & & A1 & A2 & A3 & & B1 & B2 & B4 \\
\hline & & I & I & $\mathbf{I} / \mathbf{M}$ & & $\mathbf{S} / \mathbf{U}$ & $\mathbf{I} / \mathbf{M}$ & $\mathbf{S}$ \\
\hline & $19+$ & 5 & 4 & 8 & $11 \dagger$ & 2 & 5 & 3 \\
\hline \multicolumn{9}{|l|}{ Growth in API 50 AO on: } \\
\hline Butyrate & 95 & 100 & 100 & 100 & 82 & 100 & 100 & 33 \\
\hline$n$-Valerate & 100 & 100 & 100 & 100 & 91 & 100 & 100 & 67 \\
\hline Isovalerate & 100 & 100 & 100 & 100 & 0 & 0 & 0 & 0 \\
\hline Malonate & 95 & 80 & 100 & 100 & 100 & 100 & 100 & 100 \\
\hline Maleate & 85 & 80 & 71 & 75 & 100 & 100 & 100 & 100 \\
\hline Glutarate & 90 & 100 & 100 & 100 & 100 & 100 & 100 & 100 \\
\hline Sebacate & 20 & 0 & 43 & 38 & 0 & 0 & 0 & 0 \\
\hline D-Malate & 95 & 100 & 85 & 88 & 100 & 100 & 100 & 100 \\
\hline D-Tartrate & 25 & 80 & 100 & 13 & 0 & 0 & 0 & 0 \\
\hline L-Tartrate & 50 & 0 & 100 & 100 & 0 & 0 & 0 & 0 \\
\hline meso-Tartrate & 100 & 100 & 100 & 100 & 36 & 0 & 20 & 100 \\
\hline Laevulinate & 95 & 100 & 100 & 100 & 63 & 100 & 100 & 0 \\
\hline 2-Oxoglutarate & 95 & 100 & 86 & 88 & 100 & 100 & 100 & 100 \\
\hline Citraconate & 75 & 100 & 0 & 100 & 100 & 100 & 100 & 100 \\
\hline Mesaconate & 5 & 0 & 0 & 13 & 36 & 100 & 40 & 0 \\
\hline Phenylacetate & 15 & 40 & 0 & 0 & 0 & 0 & 0 & 0 \\
\hline Benzoate & 95 & 100 & 100 & 100 & 9 & 50 & 0 & 0 \\
\hline 3-Hydroxybenzoate & 5 & 0 & 0 & 0 & 0 & 0 & 0 & 0 \\
\hline 4-Hydroxybenzoate & 95 & 100 & 100 & 100 & 100 & 100 & 100 & 100 \\
\hline D-Mandelate & 5 & 0 & 0 & 0 & 0 & 0 & 0 & 0 \\
\hline L-Mandelate & 5 & 0 & 0 & 0 & 9 & 0 & 20 & 0 \\
\hline Phthalate & 5 & 0 & 0 & 0 & 0 & 0 & 0 & 0 \\
\hline Isophthalate & 5 & 0 & 0 & 0 & 0 & 0 & 0 & 0 \\
\hline Terephthalate & 5 & 0 & 0 & 0 & 9 & 50 & 0 & 0 \\
\hline \multicolumn{9}{|l|}{ Growth in API $50 \mathrm{CH}$ on: } \\
\hline Erythritol & 5 & 0 & 0 & 0 & 91 & 100 & 100 & 67 \\
\hline D-Arabinose & 11 & 20 & 0 & 0 & 18 & 0 & 40 & 0 \\
\hline L-Arabinose & 94 & 80 & 100 & 100 & 100 & 100 & 100 & 100 \\
\hline D-Xylose & 89 & 60 & 100 & 100 & 100 & 100 & 100 & 100 \\
\hline Adonitol & 5 & 0 & 0 & 13 & 91 & 100 & 100 & 67 \\
\hline Methyl $\beta$-D-xyloside & 0 & 0 & 0 & 0 & 45 & 0 & 83 & 0 \\
\hline Sorbose & 5 & 0 & 25 & 0 & 0 & 0 & 0 & 0 \\
\hline Rhamnose & 0 & 0 & 0 & 0 & 73 & 100 & 50 & 100 \\
\hline Inositol & 0 & 0 & 0 & 0 & 100 & 100 & 100 & 100 \\
\hline Sorbitol & 0 & 0 & 0 & 0 & 100 & 100 & 100 & 100 \\
\hline Methyl $\alpha$-D-glucoside & 0 & 0 & 0 & 0 & 9 & 0 & 17 & 0 \\
\hline Amygdalin & 5 & 0 & 0 & 0 & 9 & 0 & 20 & 0 \\
\hline Arbutin & 0 & 0 & 0 & 0 & 91 & 50 & 100 & 100 \\
\hline Aesculin & 100 & 100 & 100 & 100 & 91 & 100 & 83 & 100 \\
\hline Cellobiose & 5 & 0 & 0 & 13 & 9 & 0 & 17 & 0 \\
\hline Maltose & 17 & 0 & 25 & 25 & 36 & 0 & 40 & 67 \\
\hline Melibiose & 5 & 0 & 0 & 13 & 18 & 0 & 40 & 0 \\
\hline Inulin & 11 & 0 & 25 & 13 & 0 & 0 & 0 & 0 \\
\hline Raffinose & 11 & 0 & 0 & 13 & 91 & 50 & 100 & 100 \\
\hline Starch & 39 & 0 & 50 & 63 & 27 & 0 & 20 & 67 \\
\hline Xylitol & 0 & 0 & 0 & 0 & 100 & 100 & 100 & 100 \\
\hline Gentiobiose & 0 & 0 & 0 & 0 & 9 & 0 & 20 & 0 \\
\hline
\end{tabular}


Table 2 (cont.)

\begin{tabular}{|c|c|c|c|c|c|c|c|c|}
\hline \multirow{4}{*}{$\begin{array}{r}\text { Cluster... } \\
\text { Subcluster... } \\
\text { Source*... } \\
\text { No. of isolates... }\end{array}$} & \multicolumn{4}{|c|}{$\mathbf{A}$} & \multicolumn{4}{|c|}{$\mathbf{B}$} \\
\hline & & $\mathbf{A 1}$ & A2 & A3 & & B1 & B2 & B4 \\
\hline & & $\mathbf{I}$ & $\mathbf{I}$ & $\mathbf{I} / \mathbf{M}$ & & $\mathrm{S} / \mathrm{U}$ & $\mathbf{I} / \mathbf{M}$ & $\mathbf{S}$ \\
\hline & $19+$ & 5 & 4 & 8 & $11 \dagger$ & 2 & 5 & 3 \\
\hline D-Turanose & 5 & 0 & 0 & 13 & 9 & 0 & 20 & 0 \\
\hline D-Lyxose & 83 & 60 & 100 & 88 & 100 & 100 & 100 & 100 \\
\hline D-Tagatose & 5 & 0 & 0 & 13 & 9 & 0 & 20 & 0 \\
\hline D-Fucose & 5 & 0 & 0 & 0 & 9 & 50 & 0 & 0 \\
\hline L-Fucose & 11 & 0 & 0 & 13 & 18 & 0 & 0 & 67 \\
\hline L-Arabitol & 5 & 0 & 0 & 13 & 100 & 100 & 100 & 100 \\
\hline 5-Ketogluconate & 17 & 20 & 0 & 13 & 100 & 100 & 100 & 100 \\
\hline \multicolumn{9}{|l|}{ Growth in API 50 AA on: } \\
\hline Glycine & 90 & 100 & 100 & 88 & 73 & 100 & 67 & 67 \\
\hline L-Norleucine & 85 & 100 & 100 & 75 & 73 & 100 & 83 & 33 \\
\hline DL-Norvaline & 75 & 100 & 100 & 75 & 82 & 100 & 100 & 67 \\
\hline DL-2-Aminobutyrate & 10 & 0 & 0 & 13 & 27 & 0 & 40 & 33 \\
\hline L-Threonine & 75 & 60 & 75 & 88 & 100 & 100 & 100 & 100 \\
\hline L-Cysteine & 0 & 0 & 0 & 0 & 73 & 50 & 33 & 33 \\
\hline L-Methionine & 0 & 0 & 0 & 0 & 91 & 100 & 83 & 100 \\
\hline L-Histidine & 95 & 100 & 100 & 100 & 100 & 100 & 100 & 100 \\
\hline D-Tryptophan & 0 & 0 & 0 & 0 & 9 & 0 & 20 & 0 \\
\hline L-Tryptophan & 9 & 0 & 0 & 13 & 100 & 100 & 100 & 100 \\
\hline Trigonelline & 100 & 100 & 100 & 100 & 91 & 100 & 67 & 67 \\
\hline L-Ornithine & 95 & 100 & 100 & 100 & 100 & 100 & 100 & 100 \\
\hline L-Lysine & 95 & 100 & 100 & 100 & 100 & 100 & 100 & 100 \\
\hline L-Citrulline & 75 & 100 & 75 & 63 & 100 & 100 & 100 & 100 \\
\hline DL-Kinurenine & 0 & 0 & 0 & 0 & 91 & 50 & 100 & 100 \\
\hline Creatine & 0 & 0 & 0 & 0 & 45 & 50 & 50 & 33 \\
\hline $\mathrm{DL}-3-$ Aminobutyrate & 25 & 40 & 50 & 13 & 55 & 100 & 67 & 0 \\
\hline DL-5- Iminovalerate & 95 & 100 & 100 & 100 & 95 & 100 & 100 & 100 \\
\hline 2-Aminobenzoate & 0 & 0 & 0 & 0 & 73 & 100 & 100 & 0 \\
\hline Acetamide & 10 & 40 & 0 & 0 & 19 & 0 & 0 & 67 \\
\hline Amylamine & 0 & 0 & 0 & 0 & 54 & 0 & 83 & 33 \\
\hline Spermine & 100 & 100 & 100 & 100 & 27 & 100 & 0 & 33 \\
\hline Histamine & 20 & 0 & 100 & 0 & 0 & 0 & 0 & 0 \\
\hline Tryptamine & 0 & 0 & 0 & 0 & 91 & 50 & 100 & 100 \\
\hline
\end{tabular}

* I, immature leaves; M, mature leaves; S, senescent leaves; U, undifferentiated plant leaves.

† Including single isolates.

Compounds utilized by all isolates as sole carbon sources: acetate, propionate, isobutyrate, n-caproate, heptanoate, caprylate, pelargonate, caprate, succinate, fumarate, DL-lactate, DL-glycerate, DL-3-hydroxybutyrate, L-malate, pyruvate, aconitate, citrate, D-alanine, Lalanine, L-leucine, L-isoleucine, L-valine, L-serine, L-phenylalanine, L-tyrosine, L-aspartate, L-glutamate, L-arginine, L-proline, betaine, $\beta$ alanine, DL-4-aminobutyrate, sarcosine, ethanolamine, diaminobutane, glucosamine, glycerol, ribose, galactose, glucose, fructose, mannose, mannitol, $N$-acetylglucosamine, sucrose, trehalose, $\mathrm{D}$-arabitol, gluconate, 2-ketogluconate.

Compounds not utilized as sole carbon sources by any isolates: oxalate, adipate, pimelate, suberate, azelate, glycolate, itaconate, 2hydroxybenzoate, 3-aminobenzoate, 5-aminobenzoate, urea, ethylamine, butylamine, benzylamine, L-xylose, dulcitol, methyl-D-mannose, salicin, lactose, melezitose, glycogen.

sizes were estimated by comparison with comigrating ladders of lambda DNA concatemers (Bio-Rad) and EcoRI/HindIIIdigested lambda DNA; Saccharomyces cerevisiae chromosomes (Bio-Rad) were also used as molecular mass standards.

Evaluation of PFGE gels. Enlarged prints of gels were digitized using a Summagraphics data tablet and fragment sizes determined using Molmatch computer software (UV Products).
Criteria for evaluating gels were as described by Grothues \& Tümmler (1991); a minimum of two gels were run per enzyme digest to ensure optimal resolution of all fragments.

Relatedness of isolates was determined by conducting comprehensive pair-wise comparisons of macrorestriction fragment sizes using the Dice coefficient, $S_{D}$, which is defined as the ratio of twice the number of bands common to each pair of restriction 
profiles to the total number of macrorestriction fragments in each restriction profile (Nei \& Li, 1979).

$s_{D}=2 n_{i} /\left(n_{A}+m_{B}\right)$

where $n_{A}$ and $m_{B}$ are the number of fragments in patterns $A$ and $\mathrm{B}$, respectively, and $n_{i}$ is the number of common bands. For each pair of isolates $S_{D}$ values were determined from the numbe: of common bands and total number of bands generated by all four enzymes. The statistical significance of pair-wise comparisons was evaluated using equation 13 of Grothues \& Tümmler (1991), which indicates the confidence interval for the statistical a priori similarity of macrorestriction fragment profiles:

$P\left(S_{D A B}\right)=2 /\left(\sum_{K}^{0} n_{K}+\sum_{K}^{0} m_{K}\right) \times\left[\sum_{K}^{0}\left(n_{K} m_{K} / I_{K}\right) \pm t / 2\left(\sum_{K}^{0} n_{K}\right)^{\frac{1}{2}}\right]$

where $K$ indicates the number of restriction profiles generated by $K$ independent enzyme digestions, $I$ is the number of intervals into which the range of restriction fragments is divicled and $t$ is the value of Student's $t$-distribution (see Grothues \& 'Tümmler, 1991). For both XbaI and SpeI digests, each range of restriction fragments was divided into the following intervals: $0.5 \mathrm{kbp}$ between 0 and $15 \mathrm{kbp} ; 1 \mathrm{kbp}$ between 15 and $24 \mathrm{kh}$; $2 \mathrm{kbp}$ between 25 and $50 \mathrm{kbp} ; 3 \mathrm{kbp}$ between 51 and $99 \mathrm{kh}$; $5 \mathrm{kpb}$ between 100 and $200 \mathrm{kbp}$; and $10 \mathrm{kbp}$ above $200 \mathrm{khp}$. Intervals for both $\mathrm{Pac} I$ and $S w a l$ macrorestriction profiles we ce: $2 \mathrm{kbp}$ between 4 and $52 \mathrm{kbp} ; 5 \mathrm{kbp}$ between 53 and $198 \mathrm{ktp}$; and $10 \mathrm{kbp}$ above $200 \mathrm{kbp}$.

Results from this analysis were interpreted as described by Grothues \& Tümmler (1991). Briefly, an $S_{D}$ value within the calculated confidence interval (for example $95 \%$ ) indicated that the level of similarity between a pair of isolates was no more than that expected by chance, given a random distribution of restriction sites and a given genome size. Such a result indicated that the isolates compared belong to the same species (isolates belonging to the same species are considered to have similar DNA base compositions, codon usage characteristics and genome sizes). An $S_{b}$ value outside the $95 \%$ confidence interval indicated that the isolates are either significantly more closely related (if the $S_{D}$, was higher) or less closely related (if the $S_{D}$ was lower $(P<0.05)$ than expected on the basis of genome sizes and a random distribution of restriction sites. If the $S_{D}$ value was greater than the upper value of the $95 \%$ confidence interval, then the isolates compared probably share a common ancestor (and may be assigned to the same biovar). If the $S_{D}$ value was less than the lower value of the $95 \%$ confidence interval, then the isolates compared probably do not belong to the sare taxospecies (Grothues \& Tümmler, 1991).

Genetic variation as determined by macrorestriction fragmer.t analysis was also expressed in terms of nucleotide diversity $(\pi)$, where the average number of nucleotide differences between isolates was calculated using the equation

$\pi=\left[\left(-\ln S_{D}\right) / r\right]$

where $r$ is the number of nucleotide base pairs in the restriction endonuclease recognition site (Nei \& Li, 1979).

\section{RESULTS}

\section{Biochemical and carbon source utilization characteristics}

Results from the standardized micromethod API20NE. tests showed that all isolates were positive for catalase production and assimilation of arabinose, caprate, citrate, gluconate, glucose, malate, mannitol, mannose and $N$. acetylglucosamine, but negative for $\beta$-galactosidase and indole production, acidification of glucose, reduction of nitrate to dinitrogen gas, and assimilation of adipate and phenylacetate. The seven variable reactions are listed in Table 1. On the basis of these results and using the API analytical profile index, all isolates were identified as $P$. fluorescens, the exceptions being isolates 79/2, 79/13, $79 / 45,79 / 117,114 / 95,114 / 85,148 / 146$ and $272 / 48$, which were identified to the genus Pseudomonas. The API profile index does not contain a wide selection of Pseudomonas strains and therefore the results of the API20NE tests were also compared with the determinative schemes presented by Palleroni (1984). On the basis of these schemes all isolates were identified as $P$. fuorescens, the exceptions being isolates $79 / 2,79 / 13$ and $79 / 45$ which were identified as $P$. syringae. This distinction was made primarily on the basis of the results of the arginine dihydrolase and oxidase tests.

Of the 147 auxanographic tests contained on the API strips API50CH, API50AA and API50AO, 49 carbon sources were utilized by all isolates and 21 were not utilized by any isolate (Table 2). Carbon sources which showed variable utilization are listed in Table 2. The auxanographic API system was found to be highly reproducible and duplicate strips of two randomly selected isolates were $97 \cdot 4 \%$ similar.

Numerical analysis revealed two major clusters (Fig. 1). Isolates taken from the phyllosphere on days 114, 148 and 183 were grouped into cluster $\mathrm{A}$, while isolates sampled on days 52,79 and 272 were grouped into cluster B. At a Euclidean distance of 22 , isolates in cluster A were grouped into five subclusters, and with the exception of isolate $183 / 145$, isolates subclustered according to time of isolation and to a lesser extent according to leaf type. Subcluster A1 contained isolates sampled on day 148 from immature leaves plus isolate $183 / 145$, which was also taken from immature leaves $35 \mathrm{~d}$ later. Subcluster A2 contained isolates sampled on day 183 from immature leaves, subcluster A3 contained isolates sampled on day 114 from both immature and mature leaves, and subclusters $\mathrm{A} 4$ and $\mathrm{A} 5$ each contained a single isolate isolated on sampling day 183 and 114, respectively. Subdivision of cluster B at 22 Euclids yielded four subclusters, of which B2, B3 and B4 contained isolates sampled on day 79 . Subcluster B4 contained isolates from senescing leaves, while B2 contained a mixture of isolates from mature and immature leaves. Subcluster B1 contained two isolates sampled $220 \mathrm{~d}$ apart: one from undifferentiated plants on day 52 and the other from senescing leaves on day 272.

A number of carbon sources proved useful in distinguishing between clusters $\mathrm{A}$ and $\mathrm{B}$, and included: adonitol, arbutin, benzoate, L-cysteine, erythritol, inositol, iso-valerate DL-kynurenine, L-methionine, rhamnose, sorbitol, tryptamine, L-tartrate and xylitol. Carbon sources facilitating subdivision of cluster A included: Larabitol, histamine, sebacate, starch, D-tartrate, L-tartrate and meso-tartrate. Carbon sources facilitating subdivision of cluster $B$ included: 2-aminobenzoate, DL-3- 


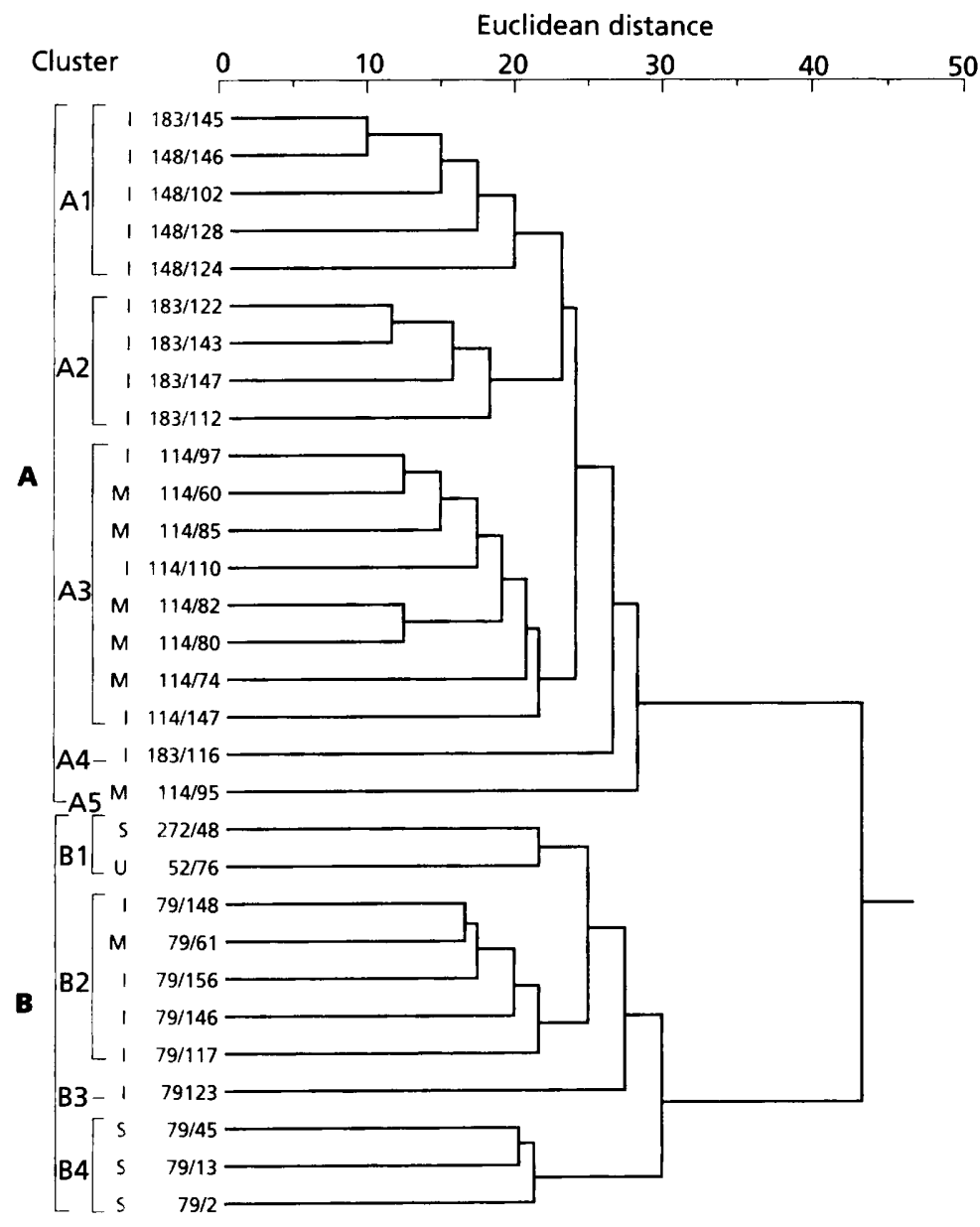

Fig. 1. Dendrogram representing the
relationship between 30 fluorescent
Pseudomonas isolates based on the ability to
assimilate 147 sole carbon sources. The
origin of isolates is indicated as follows: $U$,
leaves from plants < $53 \mathrm{~d}$ old; I, immature
leaves; $\mathrm{M}$, mature leaves; $\mathrm{S}$, senescent
leaves.

aminobutyrate, laevulinate, mesaconate, spermine, mesotartrate and terephalate (Table 2).

Comparison of the carbon source assimilation profiles with the diagnostic tables provided by Palleroni (1984) confirmed the previously assigned species designations, but also enabled identification of isolates to biovar/ pathovar level. Of the 84 variable characteristics listed in Table 4.9 by Palleroni (1984), 64 were included amongst the auxanographic tests. Isolates in cluster A bore greatest similarity to biovar $\mathrm{V}$ of $P$. fmorescens; isolates in subcluster A1 differed in their ability to assimilate acetimide, Dalanine and citraconate, and isolates in subclusters $A 2$ and A3 differed in their ability to assimilate $\mathrm{D}$-alanine and $\mathrm{L}$ tartrate. Isolates in subclusters B1 and B2 bore greatest similarity to biovar III of P. fluorescens and differed only in their ability to assimilate sucrose.

Isolates in subcluster B4 bore greatest similarity to $P$. syringae and were distinguished from $P$. viridiflava primarily on the basis of raffinose and D-tartrate assimilation; however, the ability of these isolates to assimilate Lleucine, L-tryptophan and L-tyrosine rendered them slightly atypical (Palleroni, 1984). From a total of 28 nutritional characteristics listed in Table 4.13 by Palleroni (1984) for differentiating $P$. syringae pathovars, $P$. viridiflava and $P$. cichorii, 19 were included in the current study. The assimilation pattern of isolates in subcluster B4 bore greatest similarity to $P$. syringae pv. syringae, with the only difference residing in the ability to assimilate propionate.

Carbon source assimilation data also indicated that the original species designation of $P$. aureofaciens, given by the MIDI library (version 3.30, Oct. 1990), was incorrect. All isolates differed from $P$. aureofaciens on the basis of $D$ alanine, citraconate, glycine, D-malate, phenylacetate, trigonelline and $\mathrm{D}$-xylose assimilation; furthermore, no isolate secreted the distinctive orange phenazine pigment typical of P. aureofaciens (Palleroni, 1984; Johnson \& Palleroni, 1989).

\section{Cellular fatty acid analysis}

Under standardized growth conditions all isolates displayed qualitatively similar FAME profiles. Two fatty acids, cis- 9 hexadecenoic $\left(\mathrm{C}_{16: 1}\right.$ cis $)$ acid and hexadecanoic $\left(C_{16: 0}\right)$ acid, together represented over $60 \%$ of the total fatty acid content of each isolate. The remaining fatty acid content (representing $>1 \%$ of the total) was composed of 3-hydroxydecanoic $\left(\mathrm{C}_{10: 0} 3 \mathrm{OH}\right)$, dodecanoic $\left(\mathrm{C}_{12: 0}\right), 2-$ hydroxydodecanoic $\left(\mathrm{C}_{12: 0} 2 \mathrm{OH}\right)$, 3-hydroxydodecanoic $\left(\mathrm{C}_{12: 0} 3 \mathrm{OH}\right)$ and 9,10 -methylenehexadecanoic acid $\left(\mathrm{C}_{17: 0}\right.$ cyclo) and an isomer of octadecenoic acid $\left(\mathrm{C}_{18: 1}\right)$. 


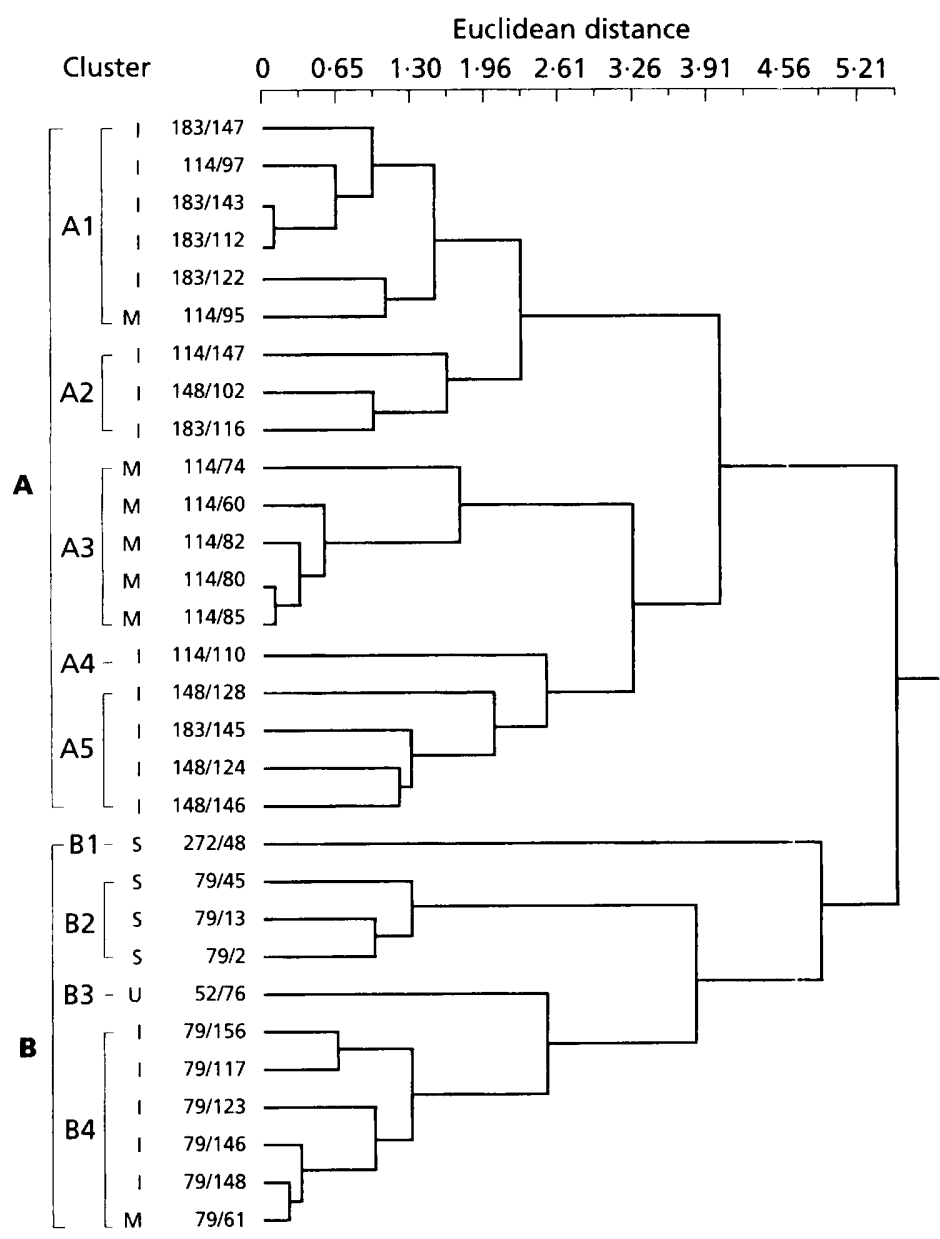

\begin{abstract}
Fig. 2. Dendrogram representing the relationship between 30 fluorescent Pseudomonas isolates based on FAME analysis. The origin of isolates is indicated as in Fig. 1.
\end{abstract}

Results from triplicate fatty acid determinations were highly reproducible, both quantitatively and qualitatively. The coefficient of variation [(standard deviation/ mean $) \times 100]$ for tripicate samples of each fatty acid representing $>4.1 \%$ of the total content was $<7.1 \%$. Individual fatty acid profiles were compared with entries from two MIS 'Aerobe' libraries: Rev. 3.3 - Oct. 1990 and Rev. 3.5 - Oct. 1991. In the initial analysis all isolates exhibited profiles closest to that of $P$. aureofaciens, but when the updated 'Aerobe' library was used (Rev. 3.5), isolates $79 / 2,79 / 13$ and $79 / 45$ were identified as $P$. s. syringae (with similarity indices of between 0.79 and 0.87 ); the remainder were identified as $P$. aureofaciens (with similarity indices ranging from 0.83 to 0.94 ), although in terms of general phenotypic properties these isolates bore closer resemblance to $P$. fuorescens (see above).

Numerical analysis revealed two main clusters (A and B) (Fig. 2) which were identical in composition to clusters $A$ and $B$ obtained on the basis of sole carbon source assimilation data (Fig. 1), but the arrangement of isolates within these clusters differed. With the exception of two cases (isolates 114/95 and 79/61) all isolates clustered according to leaf type. Within cluster $A$ five subclusters were delineated at 2 Euclids and these showed many similarities with carbon source assimilation clusters. In general subcluster A1 corresponded to carbon source assimilation subcluster A2, subcluster A3 corresponded to carbon source assimilation subcluster $\mathrm{A} 3$ and subcluster A5 corresponded to carbon source assimilation subcluster A1. Within cluster B four subclusters were delineated at 2 Euclids. Isolates 272/48 and 52/76 no longer clustered together, but isolates sampled on day 79 were subclustered into two distinct groups: B2 and B4.

Fatty acids which most distinguished isolates in cluster $\mathrm{A}$ from those in cluster $B$ were $C_{12: 0}$ and $C_{12: 0} 2 \mathrm{OH}$. In most cases the differences in individual fatty acid contents of isolates from adjacent subclusters were small (ratio < $0.5)$, but when these differences were combined, good separation between subclusters was achieved.

\section{Pyrolysis mass spectrometry}

Numerical analysis of the MS-pyrolysis data (Fig. 3) revealed a relationship between isolates similar to that indicated by numerical analysis of carbon source assimilation data and FAME data (Figs 1 and 2). MSpyrolysis delineated isolates into two clusters (A and B) and these were identical in composition to the clusters based upon carbon source assimilation and FAME analysis. With the exception of isolate $148 / 102$, isolates sampled on days 148 and 183 from immature leaves subclustered together. Isolates sampled on day 114 were 

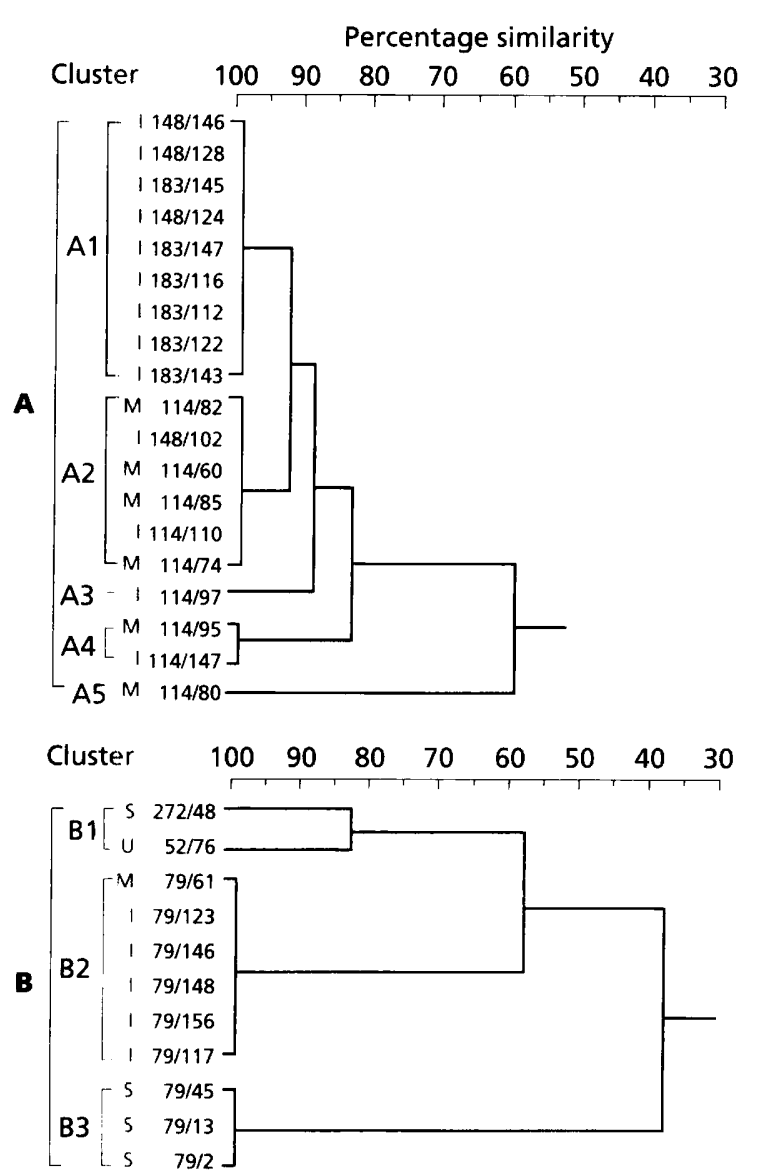

Fig. 3. Dendrograms representing the relationship between 30 fluorescent Pseudomonas isolates based on MS-pyrolysis. Isolates in clusters A and B were analysed separately to achieve better subcluster resolution. The origin of isolates is indicated as in Fig. 1.

distributed throughout four subclusters and were not clustered according to leaf type. Cluster B was subdivided into three subclusters, with isolates sampled on day 79 being divided between two subclusters. Isolates $272 / 48$ and $52 / 76$ clustered together.

\section{Total soluble protein content}

One-dimensional SDS-PAGE of whole-cell protein extracts from the 30 isolates on $6 \%$ polyacrylamide gels generated between 36 and 46 bands which ranged in size from approximately $400 \mathrm{kDa}$ to $40 \mathrm{kDa}$ (bands smaller than $40 \mathrm{k}$. Da were not used in the analysis). Duplicate gels with the same molecular mass markers yielded the same size bands $( \pm 2 \%)$, indicating the reproducibility of the method.

Numerical analysis revealed six clusters at the $90 \%$ level of similarity (Fig. 4). In general, isolates were clustered according to day of sampling, but isolate $183 / 145$ clustered with isolates sampled on day 148 , and isolates $52 / 76$ and $272 / 48$ clustered together. With few exceptions, members of a cluster shared identical protein

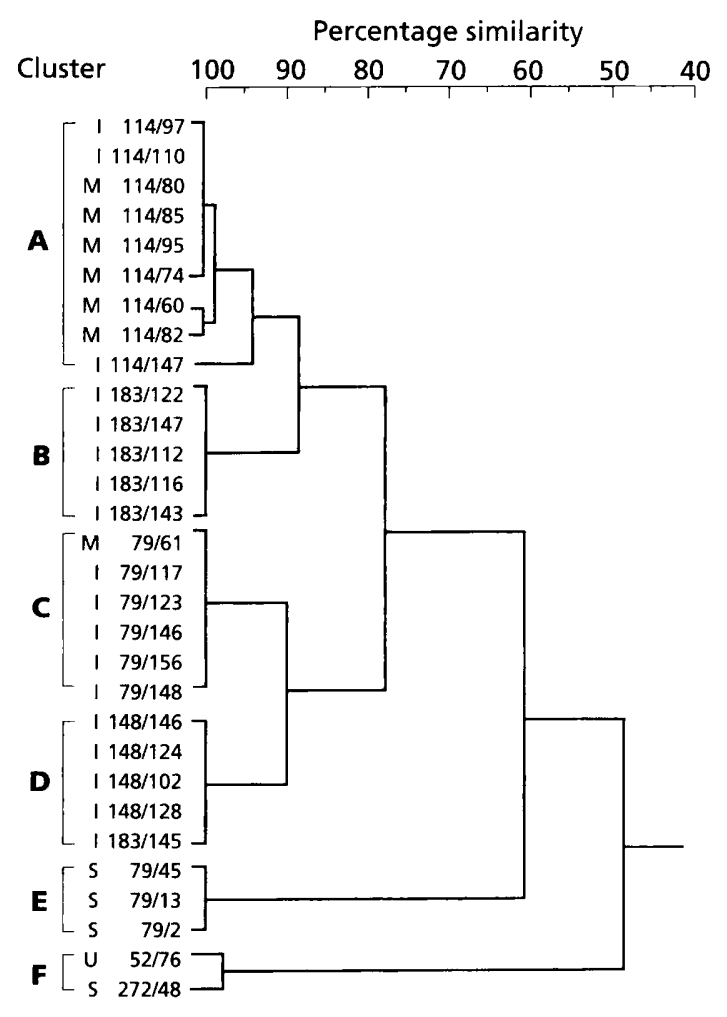

Fig. 4. Dendrogram representing the relationship between 30 fluorescent Pseudomonas isolates based on total cellular proteins resolved by $6 \%$ SDS-PAGE. The origin of isolates is indicated as in Fig. 1.

profiles. Isolates $114 / 60,114 / 82$ and $114 / 147$ possessed identical profiles to the other isolates sampled on day 114 , but isolates 114/60 and 114/82 possessed one extra band and isolate 114/147 lacked five high molecular mass bands (Fig. 5). The high molecular mass protein bands were especially useful for discriminating between isolates.

\section{Quantitative evaluation of macrorestriction patterns}

Four rare-cutting restriction endonucleases, PacI (5'TT/AATTAA), SpeI (5'-A/CTAGT), swaI (5'ATTT/AAAT) and XbaI (5'-T/CTAGA), were used to cleave the $\mathrm{G}+\mathrm{C}$-rich Pseudomonas genome and yielded between 8 and $11 ; 32$ and 47; 12 and 17 ; and 39 and 57 fragments, respectively (exclusive of doublets/triplets). The value of the extremely rare-cutting enzymes, $P a c \mathrm{I}$ and SwaI, was limited because of the small number of bands. Nevertheless, while $S_{D}$ values for $P a c I$ and $S_{w a I}$ were lower than for XbaI and SpeI, the effect of these enzymes on clustering and subsequent statistical analysis was negligible. It is important to recognize the effect that different enzymes have on the analysis of macrorestriction fragments (Giovannetti et al., 1990). The most useful data were obtained from XbaI and SpeI, which generated approximately 35 and 45 bands, respectively, and almost all bands were clearly resolved by PFGE. Enzymes which cleaved either more, or less, frequently resulted in either an overestimate, or underestimate, respectively, of the degree of similarity. 

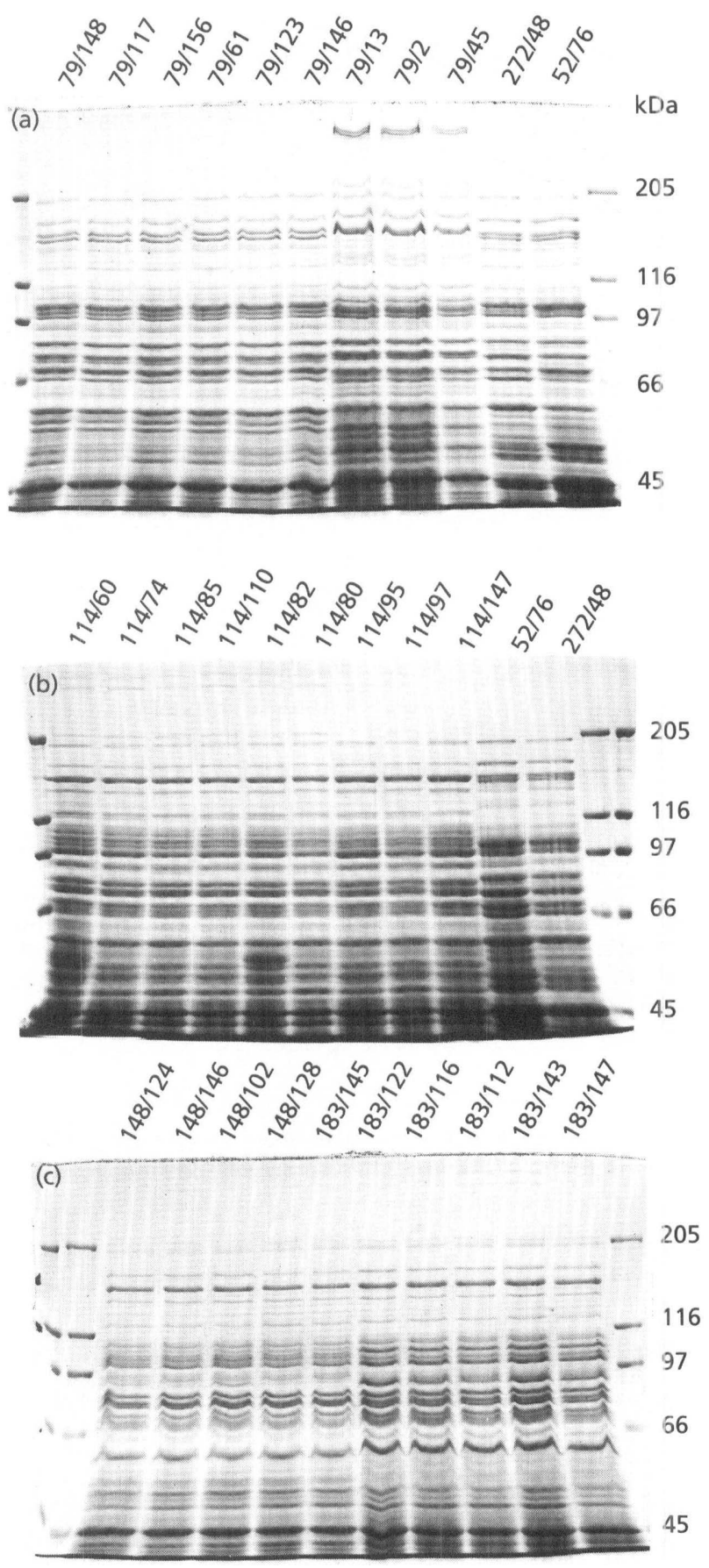

Fig. 5. SDS-PAGE (6\% polyacrylamide) of total cellular protein from Pseudomonas isolates. (a) Electrophoretic protein patterns of isolates sampled on sampling days 52, 79 and 272. (b) Electrophoretic protein patterns of isolates sampled on sampling day 114 (and repeat of $52 / 76$ and 272/48). (c) Electrophoretic protein patterns of isolates sampled on sampling days 148 and 183 . Molecular mass markers are indicated on the right.

PFGE revealed the presence of eight distinct genomic (clonal) groups designated I, II, III, IIIP, IV, V, VI, and VII (Fig. 6, Table 3), and in general, isolates sampled on the same day, from identical leaf types, were members of
Table 3. Division of fluorescent Pseudomonas isolates into genomic groups on the basis of the macrorestriction fragment analysis and approximate genome size

\begin{tabular}{|lcc|}
\hline Isolates & $\begin{array}{c}\text { Genomic } \\
\text { group }\end{array}$ & $\begin{array}{c}\text { Genome } \\
\text { size* } \\
\text { (Mbp) }\end{array}$ \\
\hline $79 / 2,79 / 13,79 / 45$ & I & $4 \cdot 2$ \\
$79 / 61,79 / 117,79 / 123,79 / 146$, & II & $4 \cdot 8$ \\
$79 / 148,79 / 156$ & III & $4 \cdot 9$ \\
$114 / 74,114 / 80,114 / 82,114 / 85$, & & \\
$\begin{array}{l}114 / 95,114 / 97,114 / 110, \\
114 / 147\end{array}$ & IIIP & $5 \cdot 3$ \\
$114 / 60$ & IV & $5 \cdot 5$ \\
$148 / 102,148 / 124,148 / 128$, & & \\
$148 / 146,183 / 145$ & V & $5 \cdot 3$ \\
$183 / 112,183 / 116,183 / 122$, & & $4 \cdot 7$ \\
$183 / 143,183 / 147$ & VI & $4 \cdot 7$ \\
$52 / 76$ & VII \\
$272 / 48$ &
\end{tabular}

* Estimate of genome size is based upon summation of Spel macrorestriction fragments.

the same genomic group. Two exceptions to this trend were isolates sampled on day 114, where genomically identical bacteria were isolated from different leaf types, and isolates sampled on day 183, where isolate 183/145 possessed the same macrorestriction profile as isolates belonging to genomic group IV (isolates sampled on day 148). Isolate $114 / 60$ is a variant of genomic group III, designated IIIP. The restriction profile of this isolate showed an additional one, or two, bands depending upon the enzyme with which the DNA was cleaved. Examination of these additional bands showed that they fluoresced with less intensity when compared to similarsized bands from the same genomic digest and it is likely that they are plasmid DNA. On the basis of band sizes from PacI, SpeI and Swal digests, the plasmid was estimated to be $400 \mathrm{kbp}$. Attempts to isolate the plasmid using the method described by Wheatcroft \& Williams (1981) proved unsuccessful, although similar-sized plasmids were isolated from control bacteria (A. K. Lilley, unpublished data). Absence of this plasmid from the other eight members of genomic group III suggests that it may have been acquired as the result of a recent in situ transfer event. The presence of the plasmid did not result in any detectable phenotypic differences.

Approximate genome sizes were obtained by summation of $S p e \mathrm{I}$ restriction fragments and ranged from $4.2 \mathrm{Mbp}$ to $5.5 \mathrm{Mbp} ;$ P. s. syringae isolates had the lowest genome size.

Distribution of restriction fragments. The distribution of restriction fragments resulting from digestion of a member of each genomic group with each of the four 

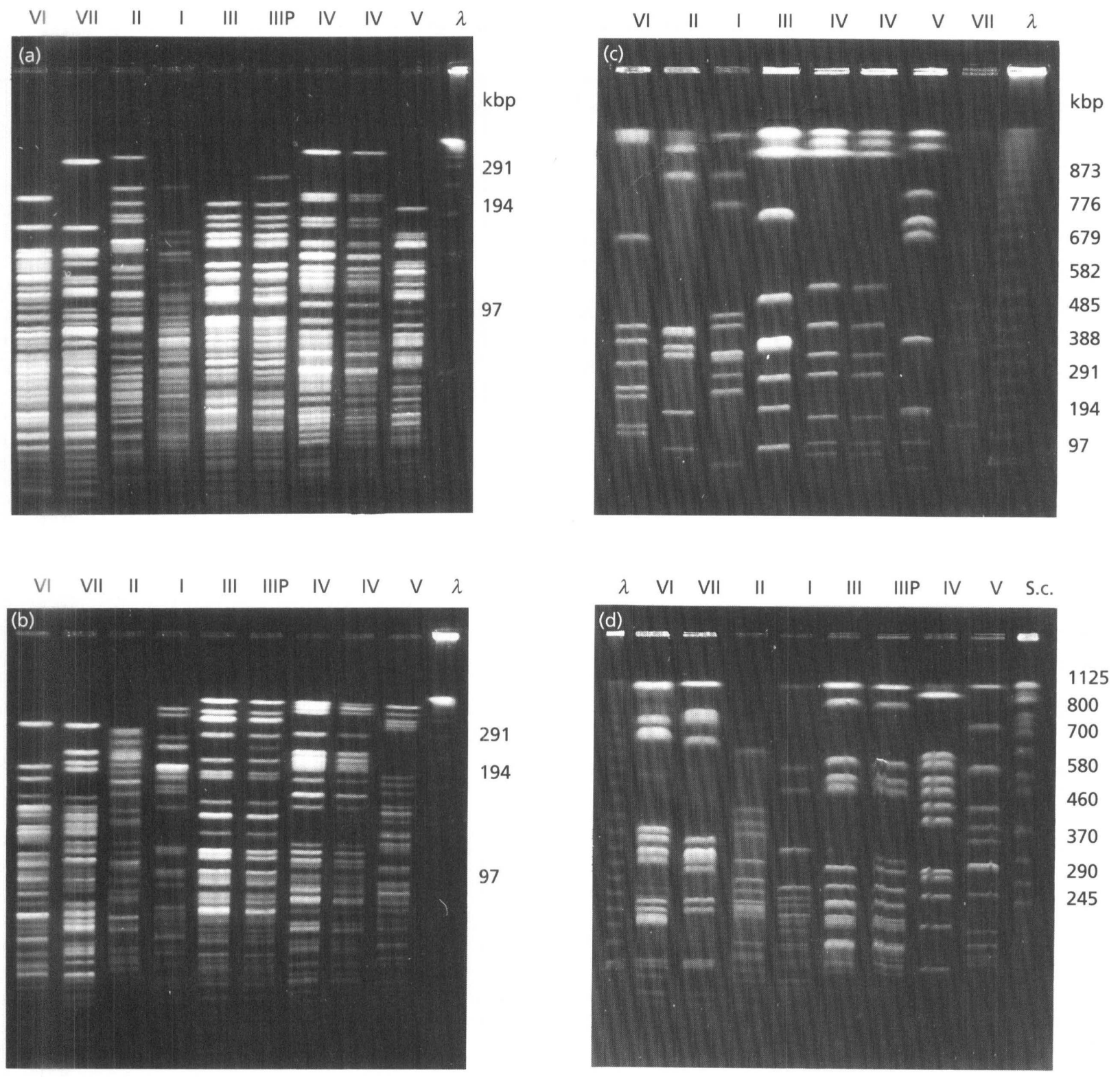

Fig. 6. Separation of Xbal (a), Spel (b), Pacl (c) and Swal (d) digests of fluorescent Pseudomonas chromosomes representative of each genomic group by contour-clamped homogeneous electric field gel electrophoresis. Representative isolates and corresponding genomic groups are: isolate $79 / 45$, genomic group 1 ; isolate $79 / 61$, genomic group II; isolate 114/110, genomic group III; isolate 114/60, genomic group IIIP; isolates $148 / 128$ and 183/145, genomic group IV; isolate 183/143, genomic group V; isolate $52 / 76$, genomic group IV; isolate $272 / 48$, genomic group VII. Fragments were resolved by using a ramped pulsed time of: $1-20 \mathrm{~s}$ for $22 \mathrm{~h}(1.25 \%$ agarose) (a); $1-25 \mathrm{~s}$ for $22 \mathrm{~h}$ ( $1.25 \%$ agarose) (b); $30-75 \mathrm{~s}$ for $21 \mathrm{~h}(1.0 \%$ agarose) (c); $30-75 \mathrm{~s}$ for $21 \mathrm{~h}$ ( $1.05 \%$ agarose) (d). The sizes of comigrating lambda concatemers and Saccharomyces cerevisiae (S.C.) chromosomes are given in kbp.

enzymes was plotted alongside the theoretical distribution of fragments calculated using the distribution function

$P(x)=\mu(1-\mu)^{x-1}$

where, assuming a random distribution of enzyme recognition sites, $\mu$ is the reciprocal of the mean fragment length, $l_{\lrcorner_{m}}$, and $x$ is fragment size (Grothues \& Tümmler, 1991). The result of this analysis is shown in Fig. 7 for SpeI, which was the only enzyme that yielded a distribution of fragments which differed significantly from the expected distribution; $\chi_{[40]}^{2}(P<0 \cdot 01)$. Deviations were apparent throughout the entire range, but maxima were detectable approximately every $20-30 \mathrm{kbp}$.

Similarity of fragment patterns. Similarity of fragment patterns was determined by pair-wise comparisons and quantified using the Dice coefficient (Table 4) (Grothues \& Tümmler, 1991). The conversion formula of Nei \& Li (1979) was used to express the data in terms of nucleotide diversity (Table 4). Confidence intervals for the statistical 
Table 4. Pair-by-pair comparisons of nucleotide diversity $(\pi)$ values and Dice coefficients $\left(S_{D}\right)$ for fluorescent pseudomonad isolates

\begin{tabular}{|c|c|c|c|c|c|c|c|c|}
\hline \multirow{2}{*}{$\begin{array}{l}\text { Genomic } \\
\text { group }\end{array}$} & \multicolumn{8}{|c|}{ Nucleotide diversity value or Dice similarity coefficient* for genomic group: } \\
\hline & I & II & III & IIIP & IV & V & VI & VII \\
\hline I & & $0 \cdot 4118$ & 0.4364 & 0.4356 & $0 \cdot 3458$ & 0.3792 & $0 \cdot 3860$ & 0.4054 \\
\hline II & $0 \cdot 1268$ & & $0 \cdot 4561$ & 0.4549 & 0.4414 & 0.4292 & 0.4661 & 0.4087 \\
\hline III & $0 \cdot 1185$ & $0 \cdot 1121$ & & 0.9799 & 0.4622 & 0.4426 & $0 \cdot 4365$ & $0 \cdot 4715$ \\
\hline IIIP & $0 \cdot 1187$ & $0 \cdot 1125$ & 0.0029 & & 0.4609 & 0.4417 & 0.4358 & 0.4701 \\
\hline IV & $0 \cdot 1517$ & $0 \cdot 1168$ & $0 \cdot 1103$ & $0 \cdot 1107$ & & 0.3930 & $0 \cdot 4310$ & $0 \cdot 4583$ \\
\hline V & $0 \cdot 1386$ & $0 \cdot 1208$ & $0 \cdot 1165$ & $0 \cdot 1167$ & $0 \cdot 1334$ & & $0 \cdot 5021$ & 0.4219 \\
\hline VI & $0 \cdot 1360$ & $0 \cdot 1091$ & $0 \cdot 1184$ & $0 \cdot 1187$ & $0 \cdot 1203$ & 0.0984 & & 0.5984 \\
\hline VII & $0 \cdot 1290$ & $0 \cdot 1278$ & $0 \cdot 1074$ & $0 \cdot 1078$ & $0 \cdot 1115$ & $0 \cdot 1233$ & 0.0734 & \\
\hline
\end{tabular}

* Values below the diagonal are $\pi$ values; those above the diagonal are $S_{D}$ values. Numbers in bold type indicate that the restriction fragment patterns are significantly more related than expected by chance $(P<0.001)$. All other pair-wise comparisons of restriction fragment patterns were neither more nor less related than expected by chance, i.e. $S_{D}$ resided within the $95 \%$ confidence interval.

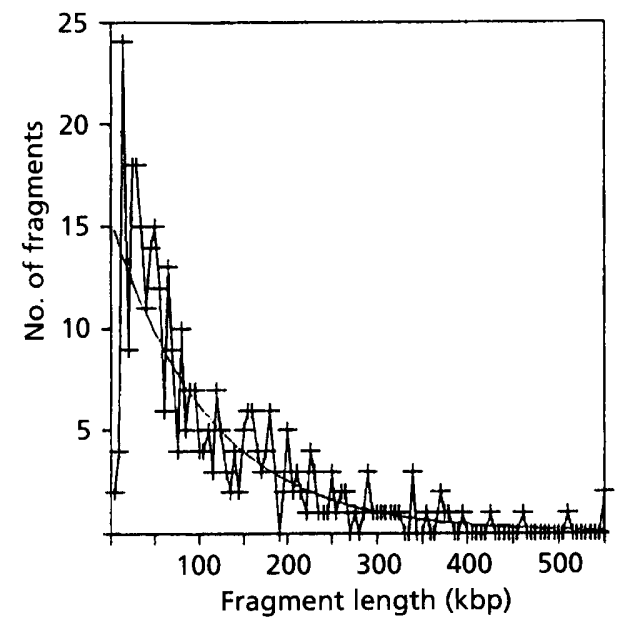

Fig. 7. Distribution of Spel restriction fragments from eight fluorescent Pseudomonas isolates-one from each genomic group. The theoretical distribution of fragments (assuming a random distribution of enzyme recognition sites) is shown by the dotted line.

correspondence of each pair of patterns were calculatec as described above and used as a means of discriminating between isolates.

A marked degree of heterogeneity was observed amongst macrorestriction profiles; however, $S_{D}$ values for all pairwise comparisons resided within the $95 \%$ confidence interval, indicating that all isolates are members of the same taxospecies (Grothues \& Tümmler, 1991). Only two pairs of macrorestriction profiles were found to be significantly more related than expected by chance. Isolate $114 / 60$ was closely related to isolate $114 / 80$ and the other day 114 isolates belonging to genomic group III $(P<$ $0 \cdot 001$, and two isolates sampled $220 \mathrm{~d}$ apart, 52/76 and $272 / 48$, shared more than $60 \%$ similarity and were also significantly more related than expected by chance $(P<$ 0.001).
Numerical analysis was used to group the isolates according to the percentage similarity of macrorestriction fragments as determined using $S_{D}$. Groups were clustered using the UPGMA linkage method (Sneath \& Sokal, 1973) and the dendrogram shown in Fig. 8 revealed six clusters at, or below, the $60 \%$ level of similarity. With the exception of isolates $52 / 76$ and $272 / 48$ in cluster $A$, and isolate 183/145 in cluster $C$, all isolates grouped according to sampling occasion.

No correlation was observed between macrorestriction fragment clusters and the clusters resulting from phenotypic analysis. In fact the diversity in macrorestriction fragment profiles was high, both within and between both biovars and species - there was as much variation in macrorestriction fragment profiles among $P$. fluorescens biovar $\mathrm{V}$ isolates as there was between $P$. fuorescens biovar III and P. fluorescens biovar V isolates (and indeed the variation within either $P$. fuorescens biovar III or V was as great as that detected between $P$. fuorescens and $P$. syringae).

\section{DISCUSSION}

Analysis of both phenotype and genotype has provided a unique perspective on a subgroup of the phyllosphereinhabiting fluorescent Pseudomonas population. Our initial aim was to investigate the extent of phenotypic and genotypic diversity within a sample of bacteria from the phyllosphere of sugar beet which FAME analysis had indicated were closely related. Extensive assessment of phenotypic properties using auxanographic tests, FAME analysis, MS-pyrolysis and total cellular protein profiles confirmed the relatedness of these bacteria, but also revealed internal groupings. In particular, auxanographic tests, cellular fatty acid analysis and MS-pyrolysis showed a division between isolates sampled on sampling days 114 , 148 and 183 (cluster A), and those isolated on sampling days 52, 79 and 272 (cluster B). Interestingly, all isolates in cluster A were isolated during the hottest part of the season (sampling days 114, 148 and 183) and produced 


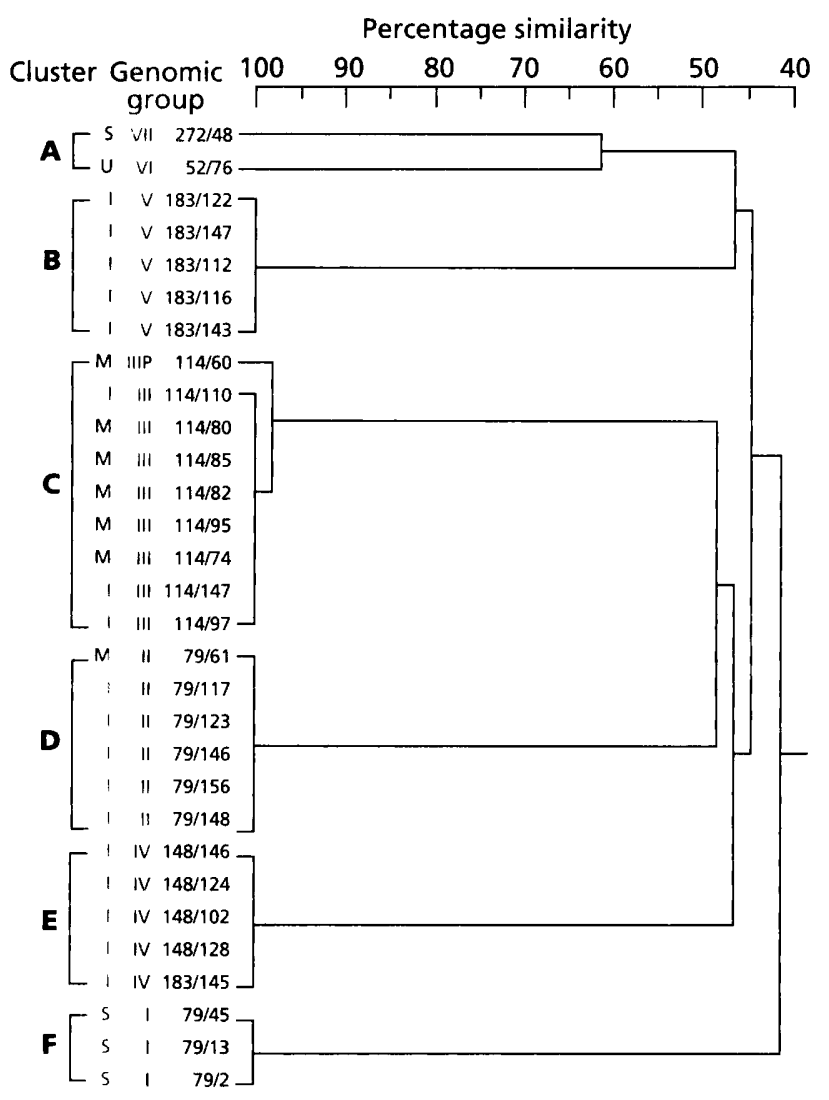

Fig. 8. Dendrogram representing the relationship between 30 fluorescent Pseudomonas isolates based on the percentage similarity of macrorestriction fragments. The origin of isolates is indicated as in Fig. 1.

copious amounts of exopolysaccharide. Exopolysaccharide production may confer a selective advantage upon phyllosphere bacteria inhabiting leaf surfaces during mid-summer by increasing their resistance to desiccation (Morgan \& Beckwith, 1939; Davenport, 1980; Robertson \& Firestone, 1992).

In general there was a good correlation between subclusters and isolate origin (day of isolation and leaf type). Fatty acid analysis showed a propensity to cluster isolates on the basis of leaf type, whereas auxanographic tests resulted in clustering of isolates according to day of sampling. MS-pyrolysis clustered some isolates according to leaf type, for example isolates sampled from immature leaves on days 148 and 183, but also clustered some isolates according to day of isolation. A correlation between phenotype and habitat or sampling occasion has been observed in other bacterial species, Fatty acid analysis showed that Xanthomonas maltophilia isolates sampled early in the season were phenotypically distinct from those sampled later in the season (Thompson et al., 1993b). Similarly, numerical analysis of phenotypic characteristics of $P$. s. savastanoi isolates sampled from olive leaves throughout a season showed that isolates clustered according to their origins (Ercolani, 1983, 1991). Races of $P$. s. glycinea were also shown to differ depending upon the growth stage of the host (Mew \& Kennedy, 1982).

Two methods of phenotypic analysis, namely biochemical tests (combined with carbon source assimilation analysis), and FAME analysis, enabled the isolates to be identified to the species level, or below. On the basis of biochemical tests (and carbon source assimilation data) isolates sampled on days 114,148 and 183 were identified as $P$. fluorescens biovar $\mathrm{V}$ and with the exception of isolates $79 / 45,79 / 13$ and $79 / 2$, which were identified as $P$. s. syringae, the remaining isolates were identified as $P$. fuorescens biovar III. These divisions were largely supported by the results of each method of phenotypic analysis, but the distinction between P. fuorescens biovar III and biovar $\mathrm{V}$ isolates was not clear from the results arising from numerical analysis of total cellular protein profiles. Interestingly, all the phenotypic methods showed that the $P$. s. syringae isolates bore more similarity to $P$. fuorescens biovar III than P. fluorescens biovar III isolates showed to $P$. fuorescens biovar $\mathrm{V}$ isolates.

The clusters arising from numerical analysis of FAME data bore considerable similarity to the clusters arising from numerical analysis of both carbon source assimilation data and MS-pyrolysis data; however, the species designation P. aureofaciens, assigned by the MIS 'Aerobe' library (Rev. 3.5) to all isolates, with the exception of $79 / 45,79 / 13$ and $79 / 12$, appears, on the basis of biochemical and carbon source utilization data, to have been incorrect. The identification of isolates $79 / 45,79 / 13$ and $79 / 2$ as $P$. s. syringae was in agreement with biochemical and carbon source utilization data. The ability of FAME analysis to differentiate phenotypically similar organisms is impressive, but doubt is cast, at least in some instances, on the validity of the identifications given by the MIS library. The difficulties associated with isolate identification may also reflect the complexity of Pseudomonas taxonomy (Palleroni, 1984).

The assignment of isolates to clusters/subclusters on the basis of phenotypic characters was largely supported by the results of the genomic analysis, although with the exception of total soluble protein analysis, members of a genomic group were not always clustered. For example, on the basis of carbon source assimilation data, isolates $183 / 116,114 / 95$ and $79 / 123$ did not cluster with members of their respective genomic group. In each instance, the failure to cluster all members of a genomic group was attributable to small, but cumulative differences in the rate of assimilation of carbon sources, rather than to genuine differences in the ability of particular isolates to assimilate particular carbon sources. This result therefore reflects the subjective scoring of these data and was exacerbated by the fact that the isolates within both clusters $A$ and $B$ shared marked phenotypic similarity and thus small differences in assimilation rates had a significant effect on clustering.

Error inherent within the FAME and MS-pyrolysis analytical methods, combined with the very high level of 
phenotypic similarity between isolates, may also have accounted for the lack of exact correlation between phenotypic clusters and genomic groups. However, the high correlation between habitat (leaf type) and FAME cluster suggests the possibility that some of these differences may be genuine. That phenotype can vary among members of a genomic group is demonstrated convincingly by the total soluble protein profiles of the genornic group III isolates (isolates sampled on day 114). These phenotypes were heritable and were not lost despite multiple transfers in broth culture and on agar media. Alterations in phenotype which are maintained independently of environmental signals must reflect underlying alterations in the genome (in either DNA sequence or DNA conformation), but these alterations would go undetected unless either a $P a c \mathrm{I}, S_{p e I} \mathrm{I}, S_{w a I}$ or $\mathrm{XbaI}$ enzyrne recognition sequence was altered. A significant aspect of the discovery of variable phenotypes within genomic group III is that it provides evidence of intraclonal polymorphism in the natural environment. This adds further credence to a recent hypothesis which argues that production of phenotypic variants within a clonal bacterial population reflects an adaptive strategy which facilitates genetic adaptation of clonal bacterial populations to unpredictable environmental change (Rainey it al., 1993a; Moxon et al., 1994).

Macrorestriction fragment analysis is a powerful method for investigating bacterial population structure and phylogeny (Arbeit et al., 1990; Böhm \& Karch, 1992; Harsono et al., 1993; Grothues \& Tümmler, 1991; Rainey et al., 1994b). It overcomes the problems associated with frequently-cleaving restriction endonucleases and unlike RFI,P analysis, which detects only a small number of variable sites within the genome, macrorestriction fragment analysis treats the entire genome as a single highly polymorphic RFLP (Grothues \& Tümmler, 1991). The large number of detectable polymorphisms (which can be increased by using more enzymes) combined with unequivocal band resolution enables detection of a variety of alterations in DNA sequence, including mutations in both coding and noncoding regions, inversions or transpositions, and duplications or deletions (Arbeit et al., 1990). Macrorestriction fragment analysis also enabled an examination of the distribution of restriction endonuclease sites. This analysis revealed a non-random distribution of SpeI restriction sites within the study group of fluorescent Pseudomonas isolates. Non-random distribution of rare palindromes is thought to be important in determining chromosome structure and has been shown in both $P$. aeruginosa (Grothues \& Tümmler, 1991) and P. stutzeri (Rainey et al., 1994).

Variation in macrorestriction fragment profiles among the eight genomic groups was unexpectedly pronounced given the high degree of phenotypic similarity among the 30 isolates. While no two macrorestriction fragment profiles were less related than expected by chance (and therefore all isolates could be assigned to the same taxospecies), the highly divergent profiles raise questions relating to Pseudomonas taxonomy, the extent of genomic diversity within the Pseudomonas population, and the nature of the evolutionary forces operating to generate and maintain this diversity.

The so-called fluorescent pseudomonads are a notoriously complex and diverse group of bacteria and with the notable exception of $P$. aeruginosa, are highly heterogeneous (Palleroni, 1986). Recent studies using nucleic acids (Palleroni et al., 1972, 1973; Johnson \& Palleroni, 1989) have enabled subdivision of the genus into five rRNA homology groups (Palleroni, 1984) and sequence analysis of the $16 \mathrm{~S}$ rRNA molecule (Woese, 1987) has provided a clear framework for the systematic grouping of the five rRNA homology groups. Significant homogeneity exists within each rRNA group (Palleroni et al., 1973), but DNA-DNA hybridization studies have revealed marked heterogeneity among the species within each rRNA group (Johnson \& Palleroni, 1989). The results from the macrorestriction fragment analysis may reflect this low DNA homology and, if considered in the absence of phenotypic data, suggest that the isolates are only distantly related.

Similar diversity in macrorestriction profiles and poor correlation with phenotypic characters, especially carbon source assimilation ability, was observed within a collection of 17 phenotypically similar $P$. stutzeri isolates (Rainey et al., 1994). Denny et al. (1988) also observed greater genotypic diversity among a collection of $17 \mathrm{P}$. s. tomato isolates (on the basis of RFLP analysis) than was evident by allozyme analysis, and Gillings \& Fahy (1993) noted that restriction fragment diversity among $P$. (Burkbolderia) solanacearum biovar N2 was greater than expected given the phenotypic uniformity of these isolates. Genomic analysis of $P$. solanacearum has also revealed a poor correlation between genotypic and phenotypic characteristics (Cook et al., 1989, 1991; Hayward, 1991 ; Seal et al., 1993; Gillings \& Fahy, 1993). It is important that future studies begin to address the reasons for this poor correlation, because it is possible that the divergent patterns are the result of intragenomic recombination (possibly mediated by insertion sequences), and/or point mutations, and thus phylogenetic reconstructions based upon RFLP data may not be correct. This issue may be partly resolved by conducting a sequence analysis of conserved housekeeping genes and comparing the results with those obtained from RFLP data.

Bacteria capable of existing in diverse and variable environments typically exhibit greatest genetic diversity. Genetic diversity within a population of $P$. (Burkbolderia) cepacia was shown to be positively correlated with habitat diversity (McArthur et al., 1988); similarly, high diversity was detected within the $P$. s. syringae population - a plant pathogen with a broad host range (Denny et al., 1988). Substantial genetic variation was also detected within a population of Deinococcus radiopugans isolated from soil (Masters et al., 1991), Rbizobium leguminosarum biovar phaseoli isolated both from individual host plants in Mexico (Souza et al., 1992) and from host plants isolated throughout the Americas (Piñero et al., 1988), Bacillus 
subtilis collected from the desert (Istock et al., 1992), Janthinobacterium lividum from streams (Saeger \& Hale, 1993), Xanthomonas oryzae from plant surfaces (Leach $e t$ al., 1992) and Erwinia chrysanthemi isolated from a variety of different plant species taken from different geographical locations (Boccara et al., 1991). This contrasts markedly with the low genetic diversity often found within pathogen populations where, as a consequence of host or strain specificity, the pathogen occupies a narrow ecological niche. Analysis of the population structure of the highly specialized potato pathogen Clavibacter michiganense subsp. setidonicus showed limited genetic diversity and an essentially clonal population structure (Mogen et al., 1990), similarly, the P. s. tomato population was also shown to be genetically homogeneous (Denny et al., 1988). Genetic diversity within populations of Rhizobium leguminosarum biovar trifolii is also reported to be limited (Harrison et al., 1989).

Saprophytic epiphytes are unlikely to exhibit narrow host specificities, and given the genetic diversity of the sugar beet population and the diversity of leaf types and niches within leaves, it would be reasonable to expect the population of phyllosphere-inhabiting pseudomonads to be genetically diverse. Such an expectation is consistent with our experimental results. A genetially diverse population would have a greater potential for adaptation to environmental change (Ayala, 1982) and this is likely to be an essential requirement for survival on the leaf surface. While the sample size of the study population is too small to enable firm conclusions to be drawn about the fluorescent Pseudomonas population structure, the high intrapopulation genetic diversity combined with limited diversity per sampling occasion suggests a population which is comprised of a variety of apparently distantly related clones (genomic groups), each adapted to local conditions. Periods of intense selection could result in both the extinction of poorly adapted clonal lines and rapid proliferation of genotypes suited to the local conditions. The rate of turnover of clones (genomic groups) is unknown, but would appear to be less than $28 \mathrm{~d}$, because in only one instance was an isolate from the same genomic group found on a later sampling occasion (genomic group IV contained isolates sampled on day 148 and day 183). The extent of the distribution of individual clones throughout the crop on each sampling occasion cannot be accurately determined given the sampling regime, nevertheless, on two instances isolates from the same genomic group were isolated from different replicate samples and from different leaf types, demonstrating that isolates of genomic groups II and III were present on at least two spatially isolated plants (within a field) and on more than a single leaf type. In fact further analysis of the 1990 field season data (Thompson et al., 1993a) in light of the current study revealed that on day 114 the total Pseudomonas population on mature leaves $(42 \%$ of the total bacterial population; $1.6 \times 10^{6}$ c.f.u. per unit) was comprised entirely of genomic group III (or IIIP) isolates. Similarly, of the total Pseudomonas population on immature leaves on sampling day $114,69 \%\left(5 \cdot 3 \times 10^{7}\right.$ c.f.u. per unit $)$ belonged to genomic group III (or IIIP).
The highly divergent macrorestriction fragment profiles of the different genomic groups suggest limited intergenomic recombination within the population, but this may merely reflect the small sample size. The potential for recombination to occur in the sugar beet phyllosphere has been demonstrated both by in situ transfer of indigenous plasmids to selectable host isolates (Lilley et al., 1994; M. J. Bailey unpublished data) and by the presence of a plasmid in isolate $114 / 60$. Recombination may also have been responsible for the significant similarity between isolates 52/76 and 272/48, although the extraordinary similarity in protein profiles, combined with the fact that the chromosomes of the two isolates are of the same size, suggests the possibility that the diversity may have been generated by intragenomic recombination events.

This study has revealed the need to greatly improve our understanding of the population structure of fluorescent pseudomonads in the natural environment. Understanding the structure of a saprophytic Pseudomonas population is of prime importance for work concerned with the efficacy and safety of genetically modified bacteria intended for environmental release (Lenski, 1993), and will be invaluable in the continuing debate on the genetic structure of bacterial populations (Maynard Smith et al., 1993). In addition, such studies will facilitate the development of integrated strategies for biotechnology where isolates can be selected on the basis of phenotype and genotype and with a knowledge of how these factors influence each other and interact with the environment.

\section{ACKNOWLEDGEMENTS}

We thank N. J. Palleroni for valuable criticism of the manuscript, Kevin Purdy for assistance with isolate sampling and Sam Pinniger for preparation of dendrograms. We are also grateful to J.S. Fenlon for advice on statistical analysis and thank Horizon Instruments Ltd (Heathfield, E. Sussex) for MSpyrolysis of isolates. I.P. T. is supported by the Department of the Environment (Grant PECD 7/8/143).

\section{REFERENCES}

Arbeit, R. D., Arthur, M., Dunn, R., Kim, C., Selander, R. K. \& Goldstein, R. (1990). Resolution of recent evolutionary divergence among Eschericbia coli from related lineages: the application of pulsed field electrophoresis to molecular epidemiology. J Infect Dis 161, 230-235.

Austin, B., Goodfellow, M. \& Dickinson, C. H. (1978). Numerical taxonomy of phylloplane bacteria isolated from Lolium perenne. $J$ Gen Microbiol 104, 139-155.

Ayala, F. J. (1982). The genetic structure of species. In Perspectives on Evolution, pp. 60-82. Edited by R. Milkman. Massachusetts: Sinauer Associates.

Boccara, M., Vadel, R., Lalo, D., Lebrum, M. \& Fafay, J. F. (1991). Genetic diversity and host range in strains of Erwinia chrysantbemi. Mol Plant-Microbe Interact 4, 292-299.

Bøe, B. \& Gjerde, J. (1980). Fatty acid patterns in the classification of some representatives of the families Enterobacteriaceae and Vibroaceae. J Gen Microbiol 116, 41-49. 
Böhm, H. \& Karch, H. (1992). DNA fingerprinting of Escherichic coli O157:H7 strains by pulsed-field gel electrophoresis. J Clin Micrabiol 30, 2169-2172.

Cook, D., Barlow, E. \& Sequeria, L. (1989). Genetic diversity of $P$ seudomonas solanacearum: detection of restriction fragment length polymorphisms with DNA probes that specify virulence and the hypersensitivity response. Mol Plant-Microbe Interact 2, 113-121.

Cook, D., Barlow, E. \& Sequeria, L. (1991). DNA probes as tools for the study of host-pathogen evolution: the example of Pseudomonas solanacearum. In Advances in Molecular Genetics of Plant-Microbe Interactions, vol. 1, pp. 103-108. Edited by H. Hennecke \& D. I'. S. Verma. Dordrecht: Kluwer Academic Publishers.

Davenport, R. R. (1980). Cold-tolerant yeasts and yeast-like organisms. In Biology and Activity of Yeasts, pp. 215-230. Edited by F. A. Skinner, S. M. Passmore \& R. R. Davenport. London: Academic Press.

Denny, T. P. (1988). Phenotypic diversity in Pseudomonas syringat $\mathrm{pv}$. tomato. J Gen Microbiol 134, 1939-1948.

Denny, T. P., Gilmour, M. N. \& Selander, R. K. (1988). Genetic diversity and relationships of two pathovars of Pseudomonas syringae. J Gen Microbiol 134, 1949-1960.

Dickinson, C. H. (1986). Adaptation of microorganisms to climatic conditions affecting plant surfaces. In Microbiology of the Pbyllosplere, pp. 77-100. Edited by N. J. Fokkema \& J. Van Den Heurel. Cambridge: Cambridge University Press.

Ercolani, G. L. (1978). Pseudomonas savastanoi and other bacteria colonizing the surface of olive leaves in the field. J Gen Microbiol 109, 245-257.

Ercolani, G. L. (1983). Variability among isolates of Pseudomonas syringae pv. savastanoi from the phylloplane of the olive. $J$ Gen Microbiol 129, 901-916.

Ercolani, G. L. (1985). Factor analysis of fluctuation in populations of Pseudomonas syringae pv. savastanoi on the phylloplane of the olive. Nicrob Ecol 11, 41-49.

Ercolani, G. L. (1991). Distribution of epiphytic bacteria on olive leaves and the influence of leaf age and sampling time. Microb ticol 21, 35-48.

Gillings, M. \& Fahy, P. (1993). Genetic diversity of Pseudomonas solanacearum biovars 2 and $\mathrm{N} 2$ assessed using restriction endonuclease analysis of total genomic DNA. Plant Patbol 42, 74.4 753.

Giovannetti, L., Venture, S., Bazzicalupo, M., Fani, R. \& Materassi, R. (1990). DNA restriction fingerprint analysis of the soil bacterium Azospirillum. J Gen Microbiol 136, 1161-1166.

Goodacre, R. \& Berkeley, R. C. W. (1990). Detection of small genotypic changes in Escherichia coli by pyrolysis mass spectrometry. FEMS Microbiol Lett 71, 133-138.

Gower, J. C. (1966). Some distance properties of latent root and vector methods used in multivariate analysis. Biometrika $\mathbf{5 3}$, $325-338$.

Grothues, D. \& Tümmler, B. (1991). New approaches in genome analysis by pulsed-field gel electrophoresis: application to the analysis of Pseudomonas species. Mol Microbiol 5, 2763-2776.

Harrison, S. P., Jones, D. G. \& Young, J. P. W. (1989). Rhizobium population genetics: genetic variation within and between populations from diverse locations. J Gen Microbiol 135, 1061-1069.

Harsono, K. D., Kaspar, C. W. \& Luchansky, J. B. (1993). Comparison and genomic sizing of Escherichia coli $\mathrm{O} 157: \mathrm{H} 7$ isolates by pulsed-field gel electrophoresis. Appl Environ Microbiol 59, $3141-3144$.
Hayward, A. C. (1991). Biology and epidemiology of bacterial wilt caused by Pseudomonas solanacearum. Annu Rev Phytopatbol 29, 65-87.

Hirano, S. S. \& Upper, C. D. (1993). Dynamics, spread and persistence of a single genotype of Pseudomonas syringae relative to those of its conspecifics on populations of snap bean leaflets. Appl Environ Microbiol 59, 1082-1091.

Istock, C. A., Duncan, K. E., Ferguson, N. \& Zhou, X. (1992). Sexuality in a natural population of bacteria-Bacillus subtilis challenges the clonal paradigm. Mol Ecol 1, 95-103.

Johnson, J. L. \& Palleroni, N. J. (1989). Deoxyribonucleic acid similarities among Pseudomonas species. Int J Syst Bacteriol 39, $230-235$.

Laemmli, U. K. (1970). Cleavage of structural proteins during assembly of the head of bacteriophage T4. Nature 227, 680-685.

Leach, J. E., Rhoads, M. L., Vera Cruz, C. M., White, F. F., Mew, T. W. \& Leung, H. (1992). Assessment of genetic diversity and population structure of Xanthomonas oryzae pv. oryzae with a repetitive DNA element. Appl Environ Microbiol 58, 2188-2195.

Lenski, R. E. (1993). Assessing the genetic structure of microbial populations. Proc Natl Acad Sci US A 90, 4334-4336.

Lilley, A. K., Fry, J. C., Day, M. J. \& Bailey, M. J. (1994). In situ transfer of exogenously isolated plasmid between Pseudomonas spp. in sugar beet rhizosphere. Microbiology 140, 27-33.

Lindow, S. E. (1993). Novel method for identifying bacterial mutants with reduced epiphytic fitness. Appl Environ Microbiol 59, 1586-1592.

Masters, C. I., Murray, R. G. E., Moseley, B. E. B. \& Minton, K. W. (1991). DNA polymorphisms in new isolates of 'Deinococcus. radiopugnans'. J Gen Microbiol 137, 1459-1469.

Maynard Smith, J., Smith, N. H., O'Rourke, M. \& Spratt, B. G. (1993). How clonal are bacteria? Proc Natl Acad Sci USA 90, 4384-4388.

McArthur, J. V., Kovacic, D. A. \& Smith, M. H. (1988). Genetic diversity in natural populations of a soil bacterium across a landscape gradient. Proc Natl Acad Sci US A 85, 9621-9624.

McClelland, M., Hanish, J., Nelson, M. \& Patel, Y. (1988). KGB : a single buffer for all restriction nucleases. Nucleic Acids Res 16, 364.

Mew, T. W. \& Kennedy, B.W. (1982). Seasonal variation in populations of pathogenic pseudomonads on soybean leaves. Phytopatbology 72, 103-105.

Miller, L. \& Berger, T. (1985). Bacterial identification by gas chromatography of whole cell fatty acids. Hewlett-Packard application note 228-241. Avondale, PA: Hewlett-Packard Co.

Mogen, B. D., Olson, H. R., Sparks, R. B., Gudmestad, N. C. \& Oleson, A. E. (1990). Genetic variation in strains of Clavibacter michiganense subsp. sepedonicum: polymorphisms in restriction fragments containing a highly repeated sequence. Pbytopathology 80 , $90-96$.

Morgan, H. R. \& Beckwith, T. D. (1939). Mucoid dissociation in the colon-typhoid-Salmonella group. J Infect Dis 65, 113-124.

Moxon, E. R., Rainey, P. B., Nowak, M. A. \& Lenski, R. E. (1994). Adaptive evolution of highly mutable loci in pathogenic bacteria. Curr Biol 4, 24-33.

Nei, M. \& Li, W.-H. (1979). Mathematical model for studying genetic variation in terms of restriction endonucleases. Proc Natl Acad Sci USA 76, 5269-5273.

Orr, K., Gould, F. K., Sisson, P. R., Lightfoot, N. F., Freeman, R. \& Burdess, D. (1991). Rapid inter-strain comparison by pyrolysis mass spectrometry in nosocomial infection with Xantbomonas maltophilia. J Hosp Infect 17, 187-195. 
O'Sullivan, D. B. \& O'Gara, F. (1992). Traits of fluorescent Pseudomonas spp. involved in suppression of plant root pathogens. Microbiol Ret 56, 662-676.

Palleroni, N. J. (1984). Family I. Pseudomonadaceae. In Bergey's Manual of Systematii Bacteriology, vol. 1, pp. 140-218. Edited by N. R. Krieg \& J. G. Holt. Baltimore: Williams \& Wilkins.

Palleroni, N. J. (1986). Taxonomy of Pseudomonads. In The Bacteria, vol. X, pp. 3 25. Edited by I. C. Gunsalus. Orlando, FL: Academic Press.

Palleroni, N. J. \& Doudoroff, M. (1972). Some properties and taxonomic subdivisions of the genus Pseudomonas. Annu Rev Phytopathol 10, 73-100.

Palleroni, N. J., Kunisawa, R., Contopoulou, R. \& Doudoroff, M. (1973). Nucleic acid homologies in the genus Pseudomonas. Int J Syst Bacteriol 23, 333-339.

Rainey, P. B., Brodey, C. L. \& Johnstone, K. (1993a). A gene cluster encoding. three high molecular weight proteins is required for synthesis of tolaasin by the mushroom pathogen Pseudomonas tolaasii. Mol Micribiol 8, 643-652.

Rainey, P. B., Moxon, E. R. \& Thompson, I. P. (1993b). Intraclonal polymorphism in bacteria. Adv Microb Ecol 13, 263-300.

Rainey, P. B., Thompson, I. P. \& Palleroni, N. J. (1994). Genome and fatti acid analysis of Pseudomonas stutzeri. Int J Syst Bacteriol 44, 54-61.

Piñero, D., Martinez, E. \& Selander, R. K. (1988). Genetic diversity and relationships among isolates of Rhizobium leguminosarum biovar phaseoli. Appl Environ Microbiol 54, 2825-2832.

Robertson, E. B. \& Firestone, M. K. (1992). Relationship between desiccation and exopolysaccharide production in a soil Pseudomonas sp. Aphl Environ Microbiol 58, 1284-1291.

Saeger, J. L. \& Hale, A. B. (1993). Genetic variation within a lotic population of Janthinobacterium lividum. Appl Environ Microbiol 59, 2214. 2219.

Seal, S. E., Jackson, L. A., Young, J. P. W. \& Daniels, M. J. (1993). Differc ntiation of Pseudomonas solanacearum, P. syzygii, P. pickettii and the blood disease bacterium by partial $16 \mathrm{~S}$ rRNA sequencing: construction of oligonucleotide primers for sensitive detection by polymerase chain reaction. J Gen Microbiol 139, 1587-1594.

Sneath, P. H. A. \& Sokal, R. R. (1973). Numerical Taxonomy: the Principles and Practice of Numerical Classification. San Francisco: W. H. Freeman.

Souza, V., Nguyen, T. T., Hudson, R. R., Piñero, D. \& Lenski, R. E. (1992). Hierarchical analysis of linkage disequilibrium in Rhizobium populations: evidence for sex? Proc Natl Acad Sci USA 89, 8389-8393.

Suwanto, A. \& Kaplan, S. (1989). Physical and genetic mapping of the Rhodobacter sphaeroides 2.4 .1 genome: genome size, fragment identification, and gene localization. J Bacteriol 171, 5840-5849.

Thompson, I. P., Bailey, M. J., Fenlon, J. S., Fermor, T. R., Lilley, A. K., Lynch, J. M., McCormack, P. J., McQuilken, M. P., Purdy, K. P., Rainey, P. B. \& Whipps, J. M. (1993a). Quantitative and qualitative seasonal changes in the microbial community from the phyllosphere of sugar beet (Beta vulgaris). Plant Soil 150, 177-191.

Thompson, I. P., Bailey, M. J., Ellis, R. J. \& Purdy, K. J. (1993b). Subgrouping of bacterial populations by cellular fatty acid composition. FEMS Microbiol Ecol 102, 75-84.

Van Outryve, M. F., Gossle, F. \& Swings, J. (1989). The bacterial microflora of witloof chicory (Cichorium intybus L. foliosum Hegi) leaves. Microb Ecol 18, 175-186.

Wheatcroft, R. \& Williams, P. A. (1981). Rapid methods for the study of both stable and unstable plasmids in Pseudomonas. I Gen Microbiol 124, 433-437.

Wilson, M. \& Lindow, S. E. (1993). Effect of phenotypic plasticity on epiphytic survival and colonization by Pseudomonas syringae. Appl Environ Microbiol 59, 410-416.

Woese, C. R. (1987). Bacterial evolution. Microbiol Rev 51, 221-271.

Xu, G. W. \& Gross, D. C. (1988). Physical and functional analysis of the $\operatorname{syr} A$ and $s y r B$ genes involved in syringomycin production by Pseudomonas syringae pv. syringae. J Bacteriol 170, 617-622.

Received 24 January 1994; revised 14 April 1994; accepted 5 May 1994. 